\title{
Larvae of the genus Eleodes (Coleoptera, Tenebrionidae): matrix-based descriptions, cladistic analysis, and key to late instars
}

\author{
Aaron D. Smith', Rebecca Dornburg', Quentin D. Wheeler ${ }^{3}$ \\ I Department of Biological Sciences, Northern Arizona University, PO Box 5640, Flagstaff, AZ, 86011-5640, USA \\ 2 School of Life Sciences, Arizona State University, PO Box 874501, Tempe, AZ, 85287-4501, USA 3 SUNY \\ College of Environmental Science and Forestry, 1 Forestry Drive, Syracuse, NY 13210, USA
}

Corresponding author: Aaron D. Smith (Aaron.Smith@nau.edu)

Academic editor: P. Bouchard | Received 2 July 2013 | Accepted 10 October 2013 | Published 12 June 2014

http://zoobank.org/287A4DC8-OEFC-42C6-AA55-DBB4D7A3441B

Citation: Smith AD, Dornburg R, Wheeler DD (2013) Larvae of the genus Eleodes (Coleoptera, Tenebrionidae): matrixbased descriptions, cladistic analysis, and key to late instar. In: Bouchard P, Smith AD (Eds) Proceedings of the Third International Tenebrionoidea Symposium, Arizona, USA, 2013. ZooKeys 415: 217-268. doi: 10.3897/zookeys.415.5887

\begin{abstract}
Darkling beetle larvae (Coleoptera, Tenebrionidae) are collectively referred to as false wireworms. Larvae from several species in the genus Eleodes are considered to be agricultural pests, though relatively little work has been done to associate larvae with adults of the same species and only a handful of species have been characterized in their larval state.

Morphological characters from late instar larvae were examined and coded to produce a matrix in the server-based content management system $\mathrm{mx}$. The resulting morphology matrix was used to produce larval species descriptions, reconstruct a phylogeny, and build a key to the species included in the matrix.

Larvae are described for the first time for the following 12 species: Eleodes anthracinus Blaisdell, Eleodes carbonarius (Say), Eleodes caudiferus LeConte, Eleodes extricatus (Say), Eleodes goryi Solier, Eleodes hispilabris (Say), Eleodes nigropilosus LeConte, Eleodes pilosus Horn, Eleodes subnitens LeConte, Eleodes tenuipes Casey, Eleodes tribulus Thomas, and Eleodes wheeleri Aalbu, Smith \& Triplehorn. The larval stage of Eleodes armatus LeConte is redescribed with additional characters to differentiate it from the newly described congeneric larvae.
\end{abstract}

\section{Keywords}

Tenebrionidae, larvae, matrix-based descriptions, Eleodes

Copyright A.D. Smith et al. This is an open access article distributed under the terms of the Creative Commons Attribution License (CC BY 4.0), which permits unrestricted use, distribution, and reproduction in any medium, provided the original author and source are credited. 


\section{Introduction}

Species of the genus Eleodes are among the most iconic and recognizable insects of the western United States. Flightless, almost always black in color, and medium to large sized $(\sim 10-50 \mathrm{~mm})$, Eleodes are perhaps most closely associated with head-standing. While this behavior, linked to the exudation or squirting of a concoction of noxious defensive chemicals from paired reservoirs near the tip of the abdomen, is not unique to Eleodes, it has been the source of common names for the genus such as stink or circus beetles.

Larvae of the family Tenebrionidae are known as false wireworms. Feeding on seeds, roots, and subterreanean stems, a number of them are considered agricultural pests, including Eleodes extricatus (Say, 1824), Eleodes hispilabris (Say, 1824), Eleodes obsoletus (Say, 1824), Eleodes opacus (Say, 1824), and Eleodes suturalis (Say, 1824) (Calkins and Kirk 1975). A summary of species considered agricultural pests and the crops they attack is given by Allsopp (1980). In spite of ecological and agricultural interest in false wireworms, and their potential contribution of a whole suite of characters for phylogenetic and taxonomic studies, knowledge of their morphology, development, and habits remain limited. Doyen (1988) estimated that approximately 240 genera and 300 species of darkling beetle larvae had been described which, as far as we know, remains a reasonable approximation. Of the 190+ currently valid Eleodes species, only seven have been previously described in the larval stages.

\section{Taxonomic history}

Relatively few Eleodes larvae have been described or characterized (Table 1). Gissler (1878) provided the first larval descriptions in the genus for Eleodes dentipes Eschscholtz, 1833 and Eleodes giganteus (Mannerheim, 1843). Hyslop (1912) described the larvae of Eleodes vandykei Blaisdell, 1909 (then listed as a subspecies of Eleodes letcheri) and Eleodes pimelioides Mannerheim, 1843 from the Pacific Northwest. McColloch (1918) described Eleodes tricostatus (Say), 1824. Wade and St. George (1923) described Eleodes suturalis (Say, 1824), followed closely by illustrations, without additional descriptions, of the pygidia of Eleodes carbonarius (Say, 1824), Eleodes opacus (Say, 1824), and E. tricostatus by St. George (1924). Blaisdell (1909) redescribed the larvae of E. dentipes in greater detail and described the pupa of Eleodes clavicornis Eschscholtz, 1833. The most recent larval description was provided by Thomas (1984) for Eleodes armatus LeConte, 1851. In most cases, these descriptions are insufficient to reliably diagnose Eleodes larvae to species.

\section{Matrix-based taxonomy}

A number of modern taxonomic works on insects have produced descriptions based on matrices of morphological characters, including Winterton (2009), Yoder et al. (2009), 
Table I. Previous publications describing or illustrating Eleodes larvae.

\begin{tabular}{l|c|c}
\hline \multicolumn{1}{c|}{ Species } & Publication & Remarks \\
\hline Eleodes armatus (LeConte), 1851 & Thomas1984 & $\begin{array}{c}\text { egg, larva, and pupa described, larva } \\
\text { and pupa imaged }\end{array}$ \\
\hline Eleodes dentipes (Eschscholtz), 1833 & Gissler 1878; Blaisdell 1909 & $\begin{array}{c}\text { Larva briefly described in } \\
\text { Gissler (1878); } \\
\text { larva redescribed and illustrated in } \\
\text { Blaisdell (1909) }\end{array}$ \\
\hline Eleodes giganteus (Mannerheim), 1843 & Gissler 1878 & $\begin{array}{c}\text { egg and larva characterized; larva } \\
\text { illustrated }\end{array}$ \\
\hline Eleodes opacus (Say), 1824 & St. George 1924 & $\begin{array}{c}\text { pygidium imaged; no description } \\
\text { egg, larva, and pupa described; } \\
\text { pygidium of larva imaged }\end{array}$ \\
\hline Eleodes pimelioides (Mannerheim), 1843 & Hyslop 1912 & $\begin{array}{c}\text { egg, larva, and pupa described, larval } \\
\text { natural history discussed, egg and } \\
\text { pupa imaged }\end{array}$ \\
\hline Eleodes tricostatus (Say), 1824 & Wade and St. George 1923 & $\begin{array}{c}\text { egg, larva, and pupa briefly } \\
\text { characterized, larval natural } \\
\text { history discussed; right mandible } \\
\text { and pygidium of larva imaged in } \\
\text { St. George (1924) }\end{array}$ \\
\hline Eleodes vandykei Blaisdell, 1909 1824 & Heorge 1924; & $\begin{array}{c}\text { egg, larva, and pupa described, egg, } \\
\text { larva, and pupa imaged; species listed } \\
\text { as E. letcheri vandykei }\end{array}$ \\
\hline
\end{tabular}

Talamas et al. (2011), and Mullins et al. (2012) to name a few. The advantages of this methodology include a structured and explicit differentia between the character states exhibited by each species or other taxonomic units, the ability to score new species into the matrix, an option to further utilize the matrix for phylogenetic analyses, and the capability to turn a matrix into a multi-entry key or link it to other data sources, such as an anatomy ontology. The present work is intended as a first step to describe the larvae of the genus Eleodes, define important characters for species and subgeneric differentiation, provide a first glimpse into evolutionary relationships within the genus, and provide a platform to link character states to the developing Coleoptera Anatomy Ontology (ColAO).

\section{Methods and Materials}

Morphological parameters. Measurements were taken using either digital calipers, an optical micrometer attached to a Nikon SMZ 1500 stereomicroscope, or measurement scales set in Photoshop specific to the camera and lens used to take measurements from images. Total length (TL) was measured from the anterior edge of the clypeus to the dorsomedial apex of abdominal segment IX. Prothoracic width (PW) and length (PL) were measured dorsally across the widest and longest points on the segment respectively, head capsule width (HW) was measured dorsally across the widest portion of the head (generally near the apex of the cranial stem). Terminology primarily follows Lawrence (1991). Dissections were performed using fine forceps and a sharpened \#0 insect pin. 
Photographs of specimens or characters were taken using a BK Plus or Passport Imaging system (R. Larimer, www.visionarydigital.com). Montaged images were assembled using Zerene Stacker (zerenesystems.com/stacker/) and backgrounds were cleaned up in Adobe Photoshop CS5. Confocal laser images were taken on a Zeiss LSM 710.

Rearing. Adult Eleodes specimens were hand collected from throughout the southwestern United States. Specimens were maintained in separate plastic containers for each species, locality, and collecting event on a substrate of sand. Every one to two weeks, containers were sifted for eggs and larvae. Larvae were reared on a sand/food substrate in plastic containers, with either plaster of Paris at the bottom watered though a vinyl tube to maintain a moisture gradient (Brown 1973) or with daily watering. A study detailing rearing regimes, instar numbers, and life histories for the reared species is forthcoming (Dornburg, Smith \& Wheeler, in preparation).

Matrix-based descriptions. To allow for easier direct comparisons between larvae of different species and provide a framework for the addition of larvae from more Eleodes species in the future, descriptions were produced from a morphological character matrix and edited for traditional telegraphic description format. The character matrix was built in mx (Yoder et al. 2010), based on 86 morphological characters (Appendices 1 and 2). Mx was also used to produce the initial descriptions. Single state characters included in the descriptions, were also included in the matrix. All specimens scored in the matrix were classified as late (7th-11th) instar larvae based on their size or observed number of molts. The one exception was Eleodes caudiferus, in which only third instar larvae were available.

Phylogeny. A modified subset of the morphology matrix consisting of 48 characters scored for 13 species of Eleodes larvae, plus two outgroup species (Tenebrio molitor Linnaeus and Zophobas morio (Fabricius)), was exported to TNT (Goloboff et al. 2008) and Winclada-NONA (Nixon 2002, Goloboff 1999) for phylogenetic analyses. Invariant characters and characters judged to be potentially highly variable between specimens (e.g. many characters involving color) were excluded from the analyses. Some character states were reordered and/or combined in the matrix used for analyses (Appendices 3 and 4) to reflect outgroup scoring and to clarify discrete parsimonyinformative states. Characters and states from Appendices 3 and 4 are abbreviated in the text as (character:state).

Traditional searches were run with 10,000 random additions and TBR branch swapping. New technology searches were also performed using a variety of settings for the Sectorial Search, Rachet, Drift, and Tree fusing functions. Standard bootstrap (10,000 replicates) and Bremer support were assessed in TNT.

\section{Results}

The phylogenetic analyses returned one most parsimonious tree (Fig. 1). The genus Eleodes was relatively strongly supported $(\mathrm{BS}=87$, Bremer $=8)$. Eleodes extricatus was placed at the base of the genus with the rest of the Eleodes, excluding a reversal in $E$. 


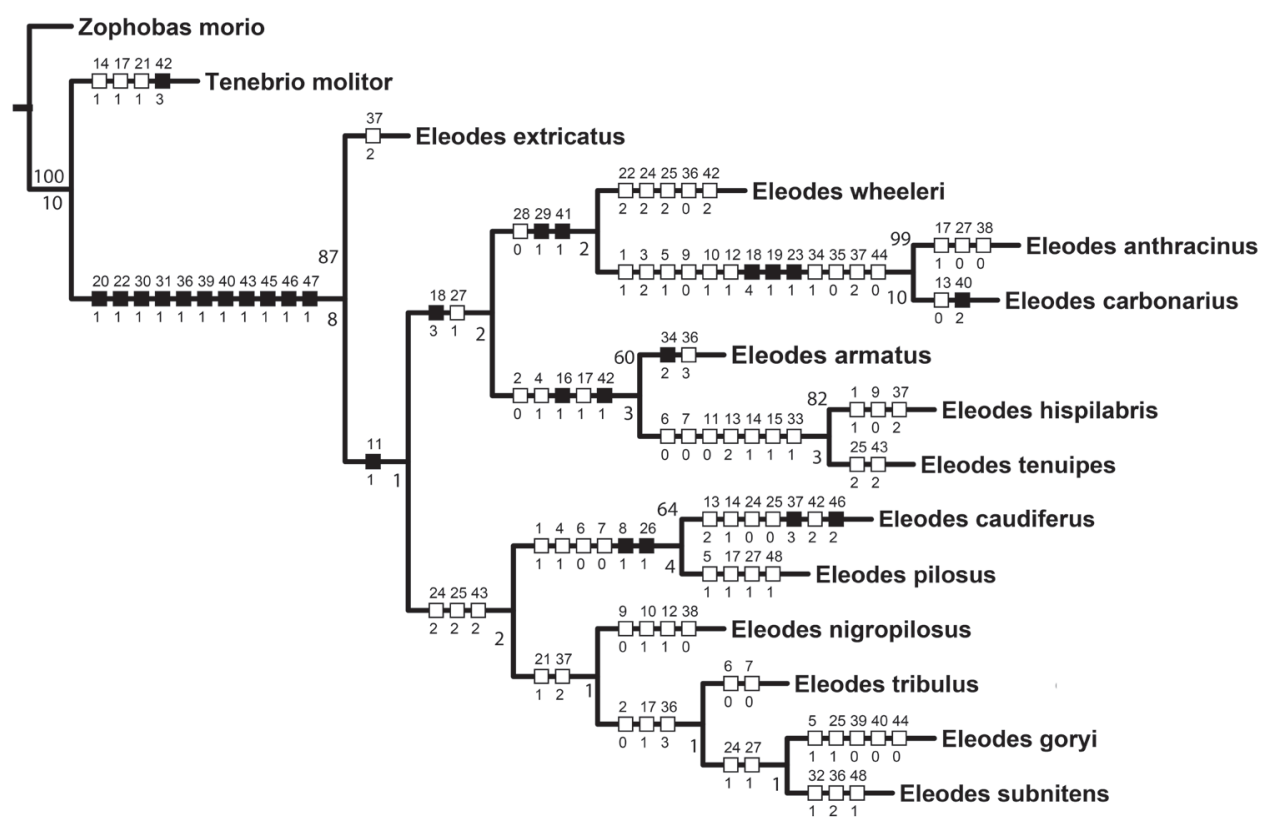

Figure I. Most parsimonious tree $(\mathrm{L}=141, \mathrm{CI}=0.5, \mathrm{RI}=.53)$ based on larval morphology. Numbers not associated with rectangles are bootstrap support values (above branches) and Bremer support values (below branches). Smaller numbers above rectangles on branches represent character number; numbers below rectangles represent character state. Black rectangles correspond to non-homoplasious character state changes. White rectangles correspond to homoplasious character state changes. All character states were unambiguously optimized on the tree.

hispilabris + E. tenuipes, having moderately punctate clypei (11:1). While the backbone of the clade had little support, several groupings were supported in the analyses.

Eleodes carbonarius + E. anthracinus, representing the only members of the subgenus Melaneleodes in the analyses, was well supported ( $\mathrm{BS}=99$, Bremer $=10)$. The presence of four long setae on the ligula (18:4, Fig. 11A) and a trapezoidal hypopharyngeal sclerome (19:1; Fig. 12A) may represent synapomorphies for the subgenus.

Eleodes armatus $+($ E. tenuipes + E. hispilabris $)$ was supported $(\mathrm{BS}=60$, Bremer=3), and represents most of the members of the nominate subgenus Eleodes in the analyses. The three species share two synapomorphies within the species sampled. One, the arrangement of anterior sensory papillae (16:1, Fig. 9B-C); and two, the presence of a distinct apical tooth on the pygidium (42:1, Fig. 14A). Eleodes caudiferus, another species currently in the nominate subgenus, is lacking both characters and was $(B S=64$, Bremer=4) supported in a sister relationship with Eleodes pilosus from the subgenus Tricheleodes. Both E. caudiferus and E. pilosus adults are found on sand dunes, and the two larval synapomorphies the species share in the matrix (8:1 and 26:1) are based on the presence of dense setation, a common adaptation to living on sand. Hence, it is possible these character codings represent convergence based on larval habitat. Eleodes caudiferus also had one unusual autapomorphy in the presence of longitudinal tomen- 
tose bands of setae along the margins of the abdominal sternites (Fig. 13A), which may also be an adaptation for living primarily on unconsolidated dunes. Eleodes tribulus was suggested as a member of the nominate subgenus (Triplehorn and Aalbu 1987), but also lacks the two synapomorphies found in other species of the subgenus. It was weakly supported in a relationship with E. goryi $+E$. subnitens from the subgenus Promus. Determining whether E. caudiferus and E. tribulus belong in the subgenus Eleodes requires further analyses of additional data.

\section{Larval descriptions}

Larvae are described or redescribed to include differential characters to separate species within the genus. Verbatim locality label data are listed with "/" indicating line breaks on the label.

\section{Eleodes Eschscholtz, 1829}

http://species-id.net/wiki/Eleodes

Material examined. Over 1,400 larval Eleodes specimens were examined for this study from 14 Eleodes species. In addition, historical descriptions and Eleodes specimens for which the species could not be confirmed due to a lack of positive association between adults and larvae also conform to the generic description provided.

Description. Integument strongly sclerotized, light tan to nearly black in color; setose, with hair-like setae throughout and spinose setae on legs and abdominal tergite IX. Thoracic and abdominal segments subcylindrical, surface coriaceous (Figs 2A-D, $3 \mathrm{~A}-\mathrm{D}, 4 \mathrm{~A}-\mathrm{C}, 5 \mathrm{~A}-\mathrm{C}, 6 \mathrm{~A}-\mathrm{C})$.

Head. Prognathous or slightly declined (Fig. $7 \mathrm{~A}-\mathrm{C}$ ), weakly dorsoventrally flattened, strongly constricted before occipital foramen. Epicranial stem one-fourth to one third head capsule length; frontal arms U-shaped or sinuate, occasionally obscured by sculpturing. Frons and dorsal portion of epicranial plates weakly to moderately rugose; punctate, punctures minute, lacking setae. Ventrolateral portions of epicranial plates setose; setae golden, erect; two stemmata present on each plate, pigmented spots often faded. Clypeus trapezoidal, often weakly transversely raised medially. Labrum with two transverse rows of six to fourteen erect setae present medially and subapically; anterior margin straight or weakly emarginate. Epipharynx (Fig. 8, $9 \mathrm{~A}-\mathrm{D}, 10 \mathrm{~A}-\mathrm{D}$ ) with stout spiniform setae along anterior margin, an anterior cluster of four to six variably arranged spinules, a subanterior transverse row of four small spinules subtended by two spinose setae and posterior cluster of six to eight small spinules; tormae symmetrical or asymmetrical. Mandible apex bidentate, mola concave. Ligula small, setation variable (Fig. 11A-C). Hypopharyngeal sclerome pentagonal or trapezoidal (Fig. 12A-B). Gula distinct, trapezoidal, widest in basal half. Antenna three segmented, cylindrical. 
Thorax. Prothoracic tergum $1.2 \times$ or more length of meso- or metaterga (Figs $2 \mathrm{~A}-\mathrm{D}$, $3 \mathrm{~A}-\mathrm{D})$; anterior transverse striated band present, generally darker than protergal disc; lateral margins with granulated band either distinct or barely visible (Fig. $7 \mathrm{~A}-\mathrm{C}$ ). Posterior transverse striated band present on all thoracic tergites. Meso- and metathoracic tergites wider than long. Mesothoracic spiracle simple, ovate, approximately $1.5 \times$ size of abdominal spiracles; reduced metathoracic spiracle visible, less than one-fourth size of mesothoracic spiracle. Legs. Prothoracic leg slightly longer, much thicker than mesoand metathoracic legs; prothoracic tarsungulus strongly sclerotized, sickle-shaped; dorsal surface of prothoracic femur with faintly indicated basal sclerotized band; dorsal surface of prothoracic tibia slightly more sclerotized than ventral surface.

Abdomen. Abdominal tergites and sternites I-VIII with transverse striated bands present along posterior margins. Abdominal sternite I setose (Fig. 13A-B). Abdominal segment IX (pygidium) triangular in dorsal view, gradually reflexed to apex, urogomphi absent, apical tooth present or absent (Fig. 14A-B); marginal row of socketed spines present around posterior two-thirds to one half of segment. Abdominal segment $\mathrm{X}$ located ventrally; pygopods short, subconical, each with erect setae.

Variation. Eleodes larvae can vary greatly in pigmentation, size, number of spines on the legs and pygidium, and the overall degree of sclerotization. Characters in the matrix relating to general integument coloration $(6,24,45,46,47,69)$ can vary greatly between specimens depending on age of specimen, length of time since last instar, and preservation method. There may also be genetic variation, though specimens from our populations were generally homogeneous.

Diagnosis. All known Eleodes larvae share the following combination of characters: head capsule weakly dorsoventrally flattened, strongly constricted before occipital foramen; prothoracic tergum $1.2 \times$ or more length of meso- or metaterga, anterior transverse striated band present, lateral margins with granulated band either distinct or barely visible; prothoracic leg slightly longer and much thicker than meso- and metathoracic legs; 8-38 socketed spines on the pygidial margin, pygopods short, subconi$\mathrm{cal}$, each with erect setae. However, the known Eleodes larvae cannot yet be separated from other Amphidorini larvae due to a lack of specimens.

\section{Subgenus Blapylis Horn, 1870}

\section{Eleodes (Blapylis) nigropilosus (LeConte, 1851)}

http://species-id.net/wiki/Eleodes_nigropilosus

Figure 4A

Material examined. Larval E. nigropilosus specimens were reared from adults with the following collecting information: "USA: CA: San Diego Co. / Oceanside beach / 33.1865, -117.3778 / 14.May.2011, ADSmith". A total of 29 eggs and larvae were reared and examined for this study, of which 34 survived to the 2 nd instar or beyond. The following description is based on a detailed examination of three 8-11th instar specimens. 


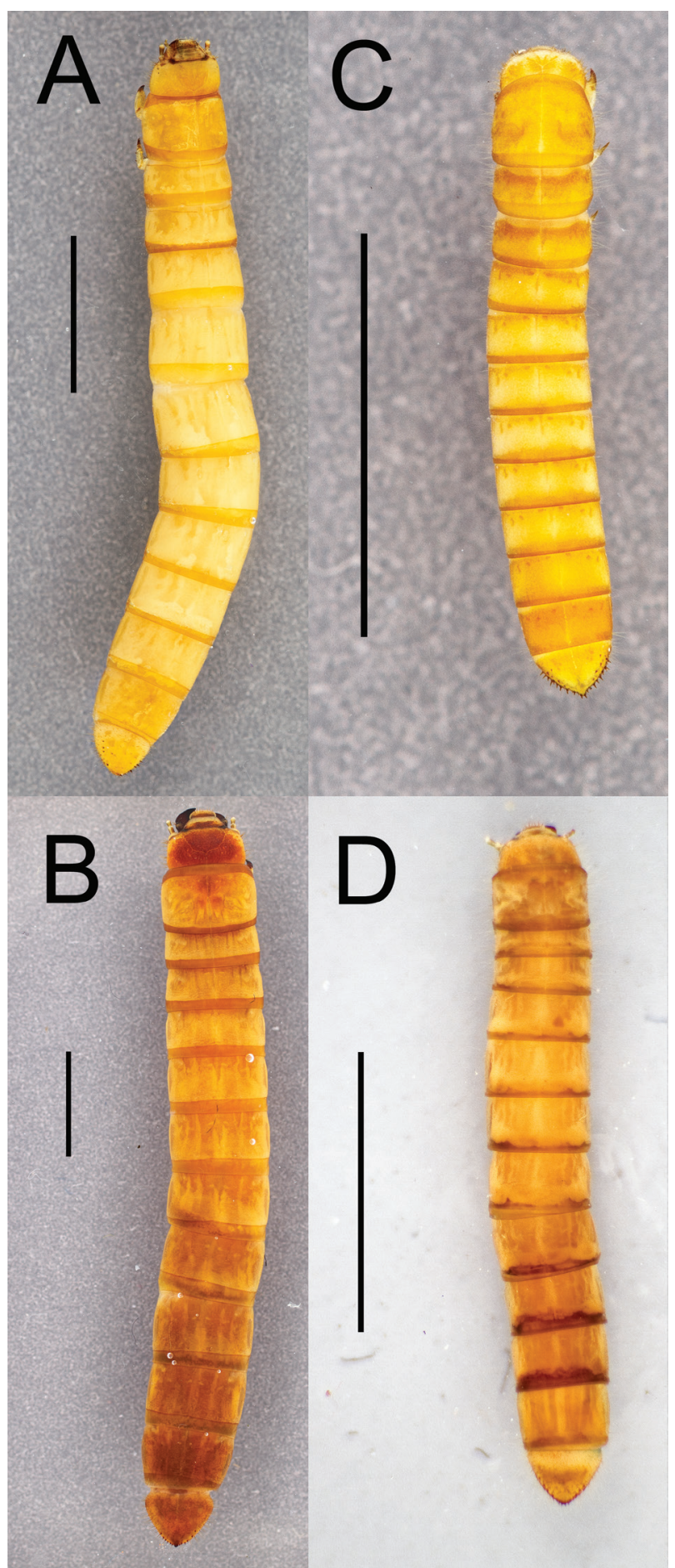

Figure 2. Dorsal habitus of four Eleodes species: A E. (Caverneleodes) wheeleri; B E. (Eleodes) armatus C E. (Eleodes) caudiferus $\mathbf{D}$ E. (Eleodes) tribulus. Scale bar $=5 \mathrm{~mm}$. 


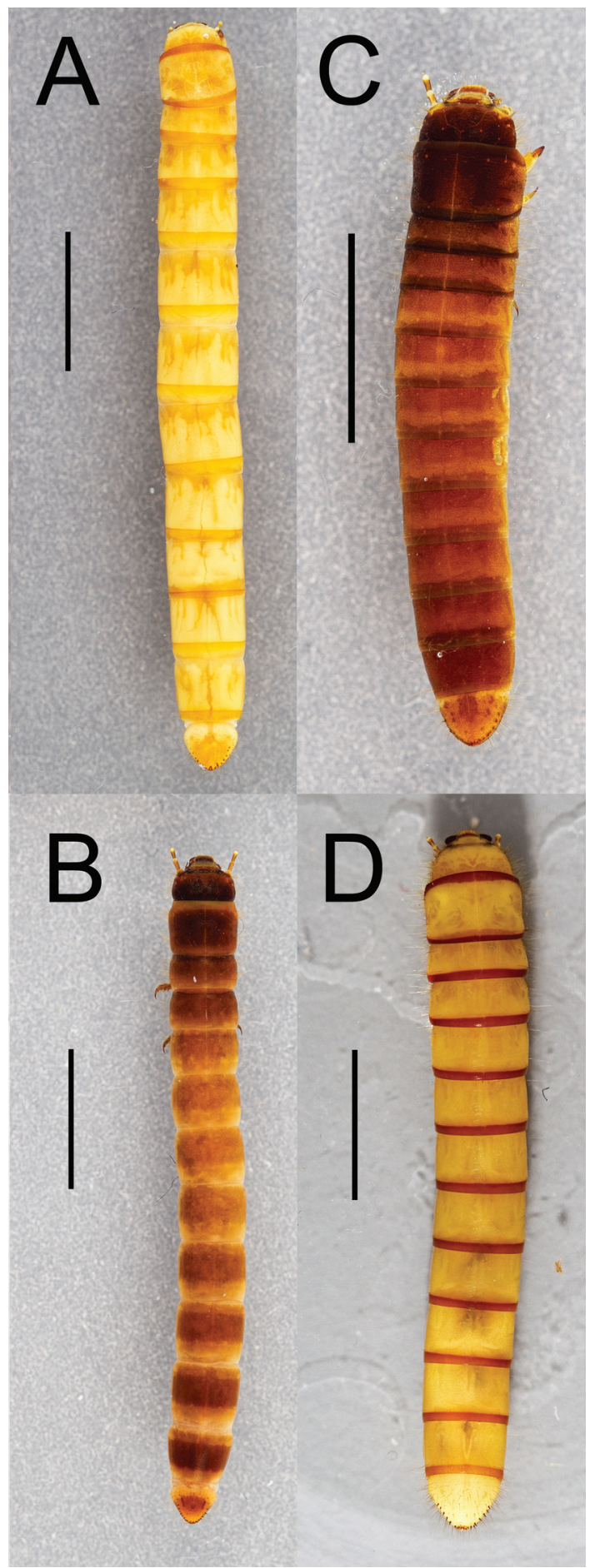

Figure 3. Dorsal habitus of four Eleodes species: A E. (Litheleodes) extricatus B E. (Melaneleodes) anthracinus $\mathbf{C}$ E. (Melaneleodes) carbonarius $\mathbf{D}$ E. (Tricheleodes) pilosus. Scale bar $=5 \mathrm{~mm}$. 
Description. TL: 12-15.9 mm, HW: 1.0-1.1 mm, PL: 1.3-1.5 mm, PW: 1.0-1.2 mm.

Head. Prognathous or weakly declined; weakly dorsoventrally flattened; width nearly equal to prothorax; sides rounded; strongly constricted before occipital foramen; color light to dark tan, same or nearly the same as body segments; punctation minute, moderately dense, separated by $2-4$ puncture diameters. Epicranial suture stem length approximately one-third head capsule length; frontal arms sinuate, not obscured by sculpturing. Frons faintly rugose. Epicranial plates weakly rugose dorsally; lateral portions moderately setose; ventral portion of each plate with row of four to five long setae along anterior margin near buccal cavity, not confluent with setae on lateral portions of plates, and a patch of short setae medially, forming a triangular pattern with its base near the anterior margin. Two stemmata present on each epicranial plate, pigmented spots often faded. Clypeus trapezoidal, not swollen, darker medially in basal half, minutely punctate, punctation moderately dense, separated by $2-4$ puncture diameters. Labrum not swollen, sides rounded, basal half more darkly pigmented, medial setal row with six to seven erect setae subapical setal row with seven to eight erect setae, anterior margin straight to weakly emarginate. Epipharynx anterior setal row with six stout spiniform setae, anterolateral margins with micro-setation; six anterior sensory papillae present, arranged in two irregular diagonal rows; four subanterior sensory papillae present, arranged as transverse row subtended by two spinose setae; eight posterior sensory papillae present, arranged in an irregular cluster. Tormae asymmetric, left torma smaller. Ligula apex and subapical dorsal surface densely micro-setose, two long subapical setae present ventrally. Hypopharyngeal sclerome pentagonal, tricuspidate. Gula distinct, trapezoidal, widest in basal half, length subequal or greater than maximum width. Antenna three segmented, cylindrical, length of first segment subequal to second.

Thorax. Thoracic tergites light tan, prothoracic sternite anterior to legs medium brown, thoracic sternites posterior to prolegs light brown. Prothoracic tergum subquadrate, $1.5 \times$ length of meso- or metaterga; anterior transverse striated band present, darker than protergal disc; lateral margins with distinct granulated band, darker than protergal disc. Posterior transverse striated band present on all thoracic tergites, forming a gradient from darker brown anteriorly to lighter brown along posterior border. Meso- and metathoracic tergites wider than long, each with a faintly indicated sclerotized transverse line present on anterior fifth. Thoracic tergites sparsely setose on dorsal surfaces, lateral margins more densely setose. Mesothoracic spiracle simple, ovate, approximately $1.5 \times$ size of abdominal spiracles; reduced metathoracic spiracle visible, less than one-fourth size of mesothoracic spiracle. Legs. Prothoracic leg slightly longer, much thicker than meso- and metathoracic legs; prothoracic tarsungulus strongly sclerotized, sickle-shaped; prothoracic trochanter with two stout spines ventromedially; prothoracic femur with ventromedial row of three spines, dorsal surface with faintly indicated basal sclerotized band; prothoracic tibia with ventromedial row of three to four spines, dorsal surface slightly more sclerotized than ventral surface. Mesotibia with two ventromedial spines. 


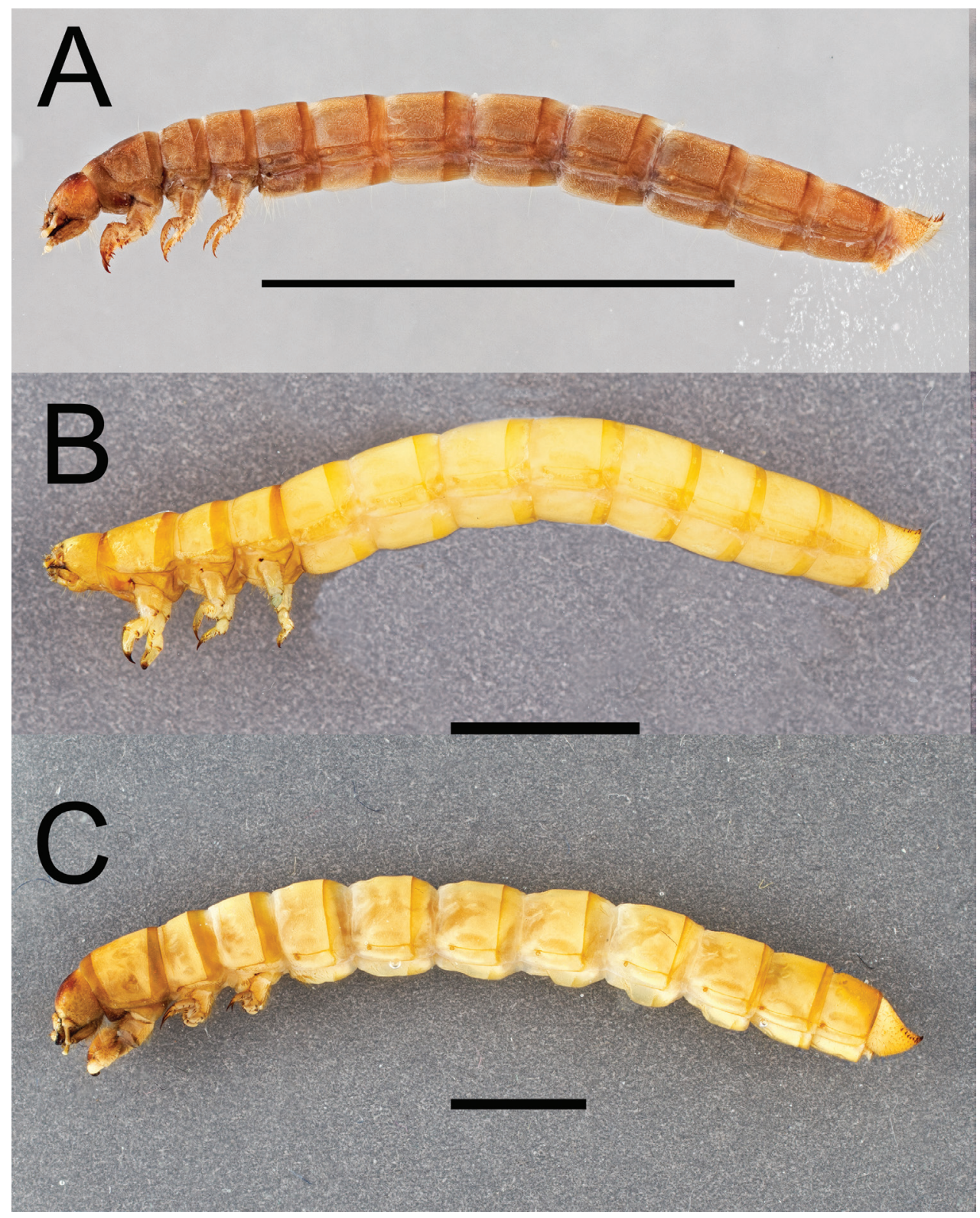

Figure 4. Lateral habitus of three Eleodes species: A E. (Blapylis) nigropilosus $\mathbf{B}$ E. (Caverneleodes) wheeleri C E. (Eleodes) armatus. Scale bar $=5 \mathrm{~mm}$.

Abdomen. Abdominal tergites and sternites light tan with darker transverse striated bands present along posterior margins of segments I-VIII, forming near contiguous band around segments, bands dark along anterior edge, fading to segment color posteriorly. Abdominal sternite I sparsely clothed in long erect setae from anterior margin 
to near midline. Abdominal laterotergites with lateral margins distinctly pigmented. Abdominal segment IX (pygidium) triangular in dorsal view, gradually reflexed to apex, urogomphi absent, apex not forming a distinct tooth, moderately clothed in short and mid length erect setae, sclerotized uniformly throughout, lacking maculations; marginal row of 14-18 socketed spines present, arranged as single row around posterior two-thirds to one half of segment. Abdominal sternites I-VIII lacking longitudinal tomentose bands along lateral margins. Pygopods short, subconical, each with 9-12 erect setae.

Diagnosis. Eleodes nigropilosus larvae can be separated from the other currently known Eleodes species by having the posterior pigmented band around the abdominal segments forming a color gradient from dark along anterior edge and fading to the color of the rest of the segment posteriorly.

\section{Subgenus Caverneleodes Triplehorn, 1975}

\section{Eleodes (Caverneleodes) wheeleri Aalbu, Smith, \& Triplehorn, 2012}

http://species-id.net/wiki/Eleodes_wheeleri

Figures $2 \mathrm{~A}, 4 \mathrm{~B}$

Material examined. Larval E. wheeleri specimens were reared from adults with the following collecting information: "USA: Arizona: Gila Co. / Tonto Natural Bridge SP / N34.3214, W111.4569 / 11.IX.2010, ADSmith". A total of 15 eggs and larvae were reared and examined for this study, with all surviving until the 2 nd instar or beyond. The following description is based on a detailed examination of five 8-11th instar specimens.

Description. Measurements: TL: 18.0-23.9 mm, PL: 1.6-2.1 mm, PW: 2.1-2.7 mm, HW: $1.8-2.3 \mathrm{~mm}$.

Head. Prognathous or weakly declined; weakly dorsoventrally flattened; width nearly equal to prothorax; sides rounded; strongly constricted before occipital foramen; color light tan, same or nearly the same as body segments; punctation minute, dense, separated by 1-2 puncture diameters. Epicranial suture stem length approximately onethird head capsule length; frontal arms sinuate, not obscured by sculpturing. Frons weakly rugose. Epicranial plates weakly rugose dorsally; lateral portions sparsely setose; ventral portion of each plate with row of six or more long setae along anterior margin near buccal cavity confluent with setae on lateral portions of plates, and a patch of short setae medially, forming a triangular pattern with its base near the anterior margin. Two stemmata present on each epicranial plate, pigmented spots often faded. Clypeus trapezoidal, swollen, darker medially in basal half, minutely punctate, punctation moderately dense, separated by $2-4$ puncture diameters. Labrum swollen, sides rounded, basal half more darkly pigmented, medial setal row with six to seven erect setae, subapical setal row with seven to eight erect setae, anterior margin straight to weakly emarginate. Epipharynx anterior setal row with six stout spiniform setae, ante- 
rolateral margins with micro-setation; four anterior sensory papillae present, arranged in two irregular longitudinal rows; four subanterior sensory papillae present arranged as a transverse row subtended by two spinose setae; eight posterior sensory papillae present, arranged in an irregular cluster. Tormae asymmetric, left torma smaller. Ligula apex lacking microsetae, two long subapical setae present ventrally, eight or more subapical setae present dorsally. Hypopharyngeal sclerome pentagonal, tricuspidate. Gula distinct, weakly trapezoidal, nearly rectangular. Antenna three segmented, cylindrical, first segment length subequal to second.

Thorax. Thoracic tergites light tan, prothoracic sternite anterior to legs light brown, thoracic sternites posterior to prolegs light tan to brown. Prothoracic tergum wider than long, $1.2 \times$ or more length of meso- or metaterga; anterior transverse striated band present, darker than protergal disc; lateral margins with very faint granulated band, nearly concolorous with protergal disc. Posterior transverse striated band present on all thoracic tergites, unicolorous brown. Meso- and metathoracic tergites wider than long, each with a faintly indicated sclerotized transverse line present on anterior fifth. Thoracic tergites sparsely setose on dorsal surfaces, lateral margins more densely setose. Mesothoracic spiracle simple, ovate, approximately $1.5 \times$ size of abdominal spiracles; reduced metathoracic spiracle visible, less than one-fourth size of mesothoracic spiracle. Legs. Prothoracic leg slightly longer, much thicker than mesoand metathoracic legs; prothoracic tarsungulus strongly sclerotized and sickle-shaped; prothoracic trochanter with two stout spines ventromedially; prothoracic femur with ventromedial row of four spines, dorsal surface with faintly indicated basal sclerotized band; prothoracic tibia with ventromedial row of five to six spines, dorsal surface slightly more sclerotized than ventral surface. Mesotibia with four to five ventromedial spines.

Abdomen. Abdominal tergites and sternites light tan with slightly darker transverse striated bands present along posterior margins of segments I-VIII, forming near contiguous unicolorous band around segments. Abdominal sternite I sparsely clothed in long erect setae along anterior margin. Abdominal laterotergites concolorous with tergites, lacking distinct pigmented margins. Abdominal segment IX (pygidium) triangular in dorsal view, gradually reflexed to apex, urogomphi absent, apex forming a small tooth, sparsely clothed in short and mid length erect setae, sclerotized uniformly throughout, lacking maculations; marginal row of 14-18 socketed spines present, arranged as single row around posterior two-thirds to one half of segment. Abdominal sternites I-VIII lacking longitudinal tomentose bands along lateral margins. Pygopods short, subconical, each with 11-15 erect setae.

Diagnosis. Eleodes wheeleri larvae can be separated from the other currently known Eleodes species by the pentagonal hypopharyngeal sclerome, the lack of a distinct apical tooth on the pygidium, the presence of two long subapical ventral setae on the ligula with eight or more setae present dorsally, and the lateral margins of the protergum with a very faint granulated band, nearly concolorous with protergal disc.

Remarks. Eleodes wheeleri was recently described (Aalbu et al. 2012) from Tonto Natural Bridge Caverns in Arizona and is known only from the type locality. 


\section{Subgenus Eleodes Eschscholtz, 1829}

\section{Eleodes (Eleodes) armatus LeConte, 1851}

http://species-id.net/wiki/Eleodes_armatus

Figures 2B, 4C, 9B, 11B

Material examined. Larval $E$. armatus specimens were reared from adults with the following collecting information: "USA: CA: Riverside Co. / Palm Desert, 38th Ave / off Washington St. / N33.7721, W116.3071 / 10.X.2010, ADSmith"; "USA: AZ: Maricopa Co. / Phoenix, E. Eugie Ave / \& 7th St. N33³6.665' / W11203.849', 418 m., / 25 May 2011, R.Dornburg." A total of 1805 eggs and larvae were reared and examined for this study, with 128 persisting to the 2 nd instar or later. The following description is based on a detailed examination of fifteen 8-11th instar specimens

Description. TL: $21.0-35.0 \mathrm{~mm}, \mathrm{HW}: 2.4-3.8 \mathrm{~mm}$, PL: $2.4-3.4 \mathrm{~mm}$, PW: 2.9-4.6 mm.

Head. Prognathous or weakly declined; weakly dorsoventrally flattened; width nearly equal to prothorax; sides rounded; strongly constricted before occipital foramen; color ferruginous, more heavily pigmented than body segments; punctation minute, dense, separated by 1-2 puncture diameters. Epicranial suture stem length approximately one-fourth head capsule length; frontal arms sinuate, not obscured by sculpturing. Frons weakly rugose. Epicranial plates weakly rugose dorsally; lateral portions moderately setose; ventral portion of each plate with row of six or more long setae along anterior margin near buccal cavity confluent with setae on lateral portions of plates, and a patch of short setae medially, forming a triangular pattern with its base near the anterior margin. Two stemmata present on each epicranial plate, pigmented spots often faded. Clypeus trapezoidal, swollen, darker medially in basal half, minutely punctate, punctation moderately dense, separated by $2-4$ puncture diameters. Labrum swollen, sides rounded, basal half more darkly pigmented, medial setal row with seven to eight erect setae, subapical setal row with seven to eight erect setae, anterior margin straight to weakly emarginate. Epipharynx (Fig. 9B) anterior setal row with six stout spiniform setae, anterolateral margins with micro-setation; six anterior sensory papillae present, arranged in two irregular rows, each with two posterior papillae and one near the anterior margin; four subanterior sensory papillae present, arranged as a transverse row subtended by two spinose setae; eight posterior sensory papillae present, arranged in an irregular cluster. Tormae asymmetric, left torma smaller. Ligula apex lacking microsetae, two long subapical setae present ventrally, eight or more subapical setae present dorsally. Hypopharyngeal sclerome pentagonal, tricuspidate. Gula distinct, trapezoidal, widest in basal half, length less than maximum width. Antenna three segmented, cylindrical, first segment longer than second.

Thorax. Thoracic tergites light tan to ferruginous, prothoracic sternite anterior to legs ferruginous, thoracic sternites posterior to prolegs light brown. Prothoracic tergum wider than long, $1.2 \times$ or more length of meso-, metaterga; anterior transverse striated band present, darker than protergal disc; lateral margins with distinct granu- 
lated band, darker than protergal disc. Posterior transverse striated band present on all thoracic tergites, unicolorous brown. Meso- and metathoracic tergites wider than long, each with a heavily sclerotized transverse line present on anterior fifth. Thoracic tergites sparsely setose on dorsal surfaces, lateral margins more densely setose. Mesothoracic spiracle simple, ovate, approximately $1.5 \times$ size of abdominal spiracles; reduced metathoracic spiracle visible, less than one-fourth size of mesothoracic spiracle. Legs. Prothoracic leg slightly longer, much thicker than meso- and metathoracic legs; prothoracic tarsungulus strongly sclerotized, sickle-shaped; prothoracic trochanter with two stout spines ventromedially; prothoracic femur with ventromedial row of six to ten spines, dorsal surface with faintly indicated basal sclerotized band; prothoracic tibia with ventromedial row of eight to eleven spines or spinose setae, dorsal surface slightly more sclerotized than ventral surface. Mesotibia with five to seven ventromedial spines.

Abdomen. Abdominal tergites and sternites light tan to ferruginous, with slightly darker transverse striated bands present along posterior margins of segments I-VIII, forming near contiguous unicolorous band around segments. Abdominal sternite I moderately clothed in long erect setae from anterior margin to near midline. Abdominal laterotergites with lateral margins distinctly pigmented. Abdominal segment IX (pygidium) triangular in dorsal view, gradually reflexed to apex, urogomphi absent, apex forming a distinct tooth, sparsely clothed in short and mid length erect setae, sclerotized uniformly throughout, lacking maculations; marginal row of 22-24 socketed spines present, arranged as single row around posterior two-thirds to one half of segment. Abdominal sternites I-VIII lacking longitudinal tomentose bands along lateral margins. Pygopods short, subconical, each with 11-15 erect setae.

Diagnosis. Eleodes armatus larvae can be separated from the other currently known Eleodes species by presence of an apical tooth on the pygidium and the absence of stout spiniform setae on the anterolateral margins of the epipharnyx.

\section{Eleodes (Eleodes) caudiferus LeConte, 1858}

http://species-id.net/wiki/Eleodes_caudiferus

Figures 2C, 5A, 13A

Material examined. Larval E. caudiferus specimens were reared from adults with the following collecting information: "USA: Arizona: Navajo Co. / dunes $-4 \mathrm{mi} N$ Chilchinbito / off route 59, el. 1738m / N36.58143, W110.06973 / 26.August.2010, ADSmith". A total of 85 eggs and larvae were reared and examined for this study, of which 53 survived untill the 2 nd instar or later. The following description is based on a detailed examination of eleven 3-5th instar specimens.

Description. TL: 7.8-12.8 mm, HW: 1.0-1.4 mm, PL: 1.0-1.8 mm, PW: 1.3$1.7 \mathrm{~mm}$.

Head. Prognathous or weakly declined; weakly dorsoventrally flattened; width narrower than prothorax; sides rounded; strongly constricted before occipital foramen; color dark tan, same or nearly the same as on body segments; punctation minute, 


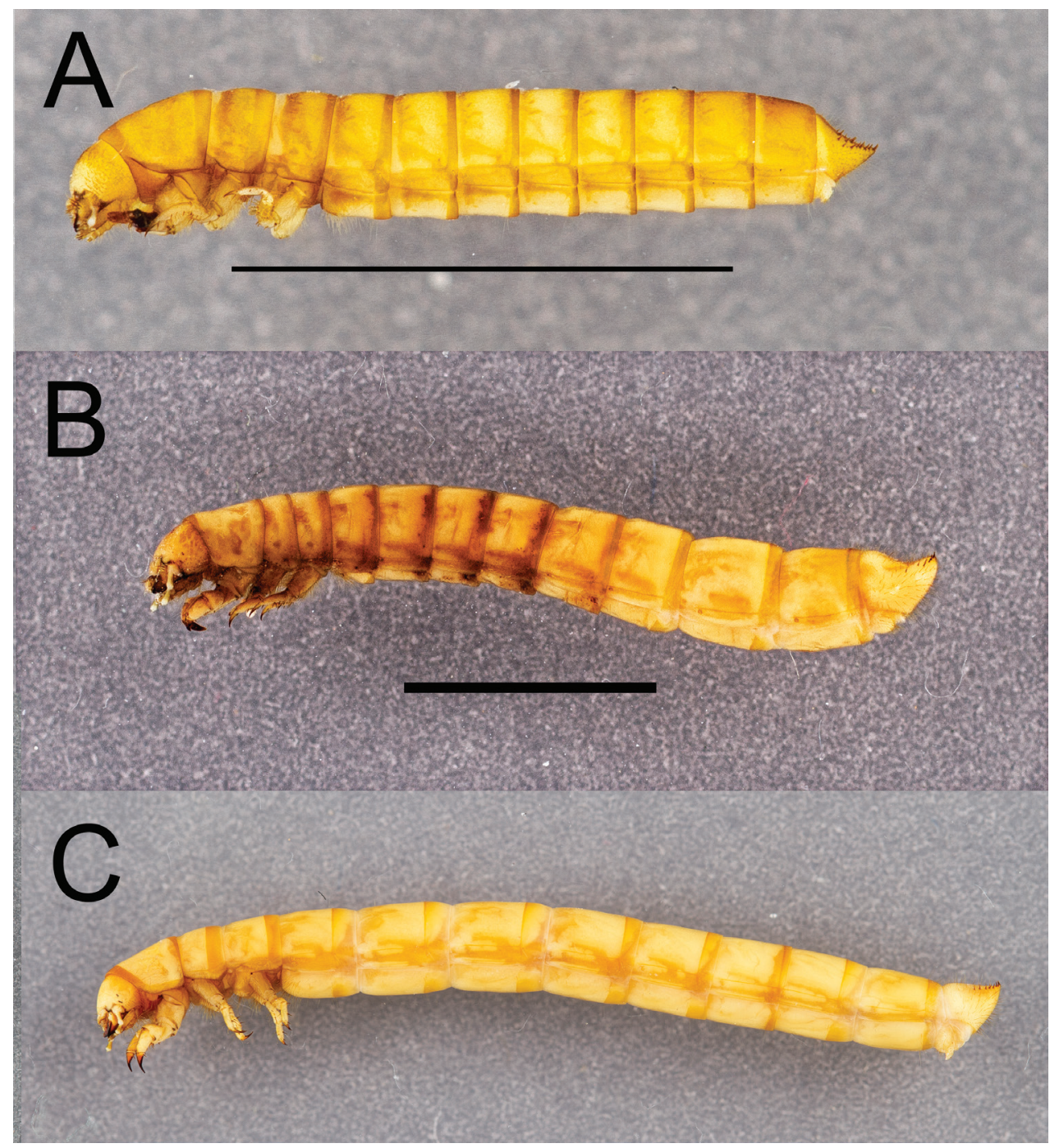

Figure 5. Lateral habitus of three Eleodes species: A E. (Eleodes) caudiferus B E. (Eleodes) tribulus C $E$. (Litheleodes) extricatus. Scale bar $=5 \mathrm{~mm}$.

moderately dense, separated by $2-4$ puncture diameters. Epicranial suture stem length approximately one-fourth to one-third head capsule length; frontal arms sinuate, not obscured by sculpturing. Frons rugose. Epicranial plates rugose dorsally; lateral portions densely setose; ventral portion of each plate with row of six or more long setae along anterior margin near buccal cavity confluent with setae on lateral portions of plates, and a patch of short setae medially, forming a triangular pattern with its base near the anterior margin. Two stemmata present on each epicranial plate, pigmented spots often faded. Clypeus trapezoidal, swollen, darker medially in basal half, minutely punctate, puncta- 
tion moderately dense, separated by $2-4$ puncture diameters. Labrum swollen, sides rounded, basal half more darkly pigmented, medial setal row with 10-14 erect setae, subapical setal row with 10-14 erect setae, anterior margin straight to weakly emarginate. Epipharynx anterior setal row with eight or more stout spiniform setae, anterolateral margins with micro-setation; six anterior sensory papillae present, arranged in two irregular rows; four subanterior sensory papillae present arranged as a transverse row subtended by two spinose setae; eight posterior sensory papillae present, arranged in an irregular cluster. Tormae symetrical or weakly asymmetric. Ligula apex densely microsetose, two long subapical setae present ventrally. Hypopharyngeal sclerome pentagonal, tricuspidate. Gula distinct, trapezoidal, widest in basal half, length less than maximum width. Antenna three segmented, cylindrical, first segment subequal to second.

Thorax. Thoracic tergites ferruginous, prothoracic sternite anterior to legs ferruginous, thoracic sternites posterior to prolegs light brown. Prothoracic tergum subquadrate, $1.5 \times$ length of meso- or metaterga; anterior transverse striated band present, darker than protergal disc; lateral margins with distinct granulated band, darker than protergal disc. Posterior transverse striated band present on all thoracic tergites, unicolorous brown. Meso- and metathoracic tergites wider than long, with sclerotized transverse line on anterior fifth absent, dense transverse band of short setae present near anterior margins of both tergites. Mesothoracic spiracle simple, ovate, approximately $1.5 \times$ size of abdominal spiracles; reduced metathoracic spiracle visible, less than one-fourth size of mesothoracic spiracle. Legs. Prothoracic leg slightly longer, much thicker than meso- and metathoracic legs; prothoracic tarsungulus strongly sclerotized, sickle-shaped; prothoracic trochanter with two stout spines ventromedially; prothoracic femur with ventromedial row of five to six spines, dorsal surface with faintly indicated basal sclerotized band; prothoracic tibia with ventromedial row of five to six spines or spinose setae, dorsal surface slightly more sclerotized than ventral surface. Mesotibia with row of three ventromedial spines.

Abdomen. Abdominal tergites and sternites light tan to ferruginous, with slightly darker transverse striated bands present along posterior margins of segments I-VIII, forming near contiguous unicolorous band around segments. Abdominal sternite I tomentose in anterior third, setae denser along near lateral margins. Abdominal laterotergites with lateral margins distinctly pigmented. Abdominal segment IX (pygidium) triangular in dorsal view, gradually reflexed to apex, urogomphi absent, apex attenuated and sclerotized, rarely forming a small tooth, sparsely clothed in short and mid length erect setae, sclerotized uniformly throughout, lacking maculations; marginal row of 28-38 socketed spines present, forming two or three irregular rows around posterior two-thirds to one half of segment, narrowing to single row around apex. Abdominal sternites I-VIII with longitudinal tomentose bands present along lateral margins. Pygopods short, subconical, each with 17-24 erect setae.

Diagnosis. Eleodes caudiferus larvae can be separated from the other currently known Eleodes species by the presence of longitudinal tomentose bands along the lateral margins of abdominal sternites I-VIII. 


\section{Eleodes (Eleodes) hispilabris (Say, 1824)}

http://species-id.net/wiki/Eleodes_hispilabris

Figures 9C, 14A

Material examined. Larval E. hispilabris specimens were reared from adults with the following collecting information: "USA: TX: El Paso County / El Paso, sand dunes off / Hwy 180/Montana Ave. / N31.82327, W106.13234 / 21-22.VIII.2010, ADSmith”. A total of 46 eggs and larvae were reared and examined for this study, with 36 surviving until the 2 nd instar or beyond. The following description is based on a detailed examination of five $8-11$ th instar specimens.

Description. TL: 21.0-32.0 mm, PL: 2.6-3.2 mm, PW: 3.0-3.7 mm, HW: 2.4$3.1 \mathrm{~mm}$.

Head. Prognathous or weakly declined; weakly dorsoventrally flattened; width narrower than prothorax; sides rounded; strongly constricted before occipital foramen; color ferruginous, more heavily pigmented than body segments; punctation minute, dense, separated by 1-2 puncture diameters. Epicranial suture stem length approximately one-fourth head capsule length; frontal arms sinuate, not obscured by sculpturing. Frons rugose. Epicranial plates rugose dorsally; lateral portions moderately setose; ventral portion of each plate with row of four to five long setae along anterior margin near buccal cavity, not confluent with setae on lateral portions of plates, with a patch of short setae medially, forming a triangular pattern with its base near the anterior margin. Two stemmata present on each epicranial plate, pigmented spots often faded. Clypeus trapezoidal, swollen, darker medially in basal half, minutely punctate, punctation dense, separated by 1-2 puncture diameters. Labrum swollen, sides rounded, basal half more darkly pigmented, medial setal row with six to seven erect setae, subapical setal row with 10-14 erect setae, anterior margin straight to weakly emarginate. Epipharynx (Fig. 9C) anterior setal row with eight or more stout spiniform setae, anterolateral margins with stout spinose setae; six anterior sensory papillae present, arranged in two irregular rows, each with two posterior papillae and one near the anterior margin; four subanterior sensory papillae present, arranged as a transverse row subtended by two spinose setae; seven to eight posterior sensory papillae present, arranged in an irregular cluster. Tormae strongly asymmetric, left torma larger. Ligula apex lacking microsetae, two long subapical setae present ventrally, eight or more subapical setae present dorsally. Hypopharyngeal sclerome pentagonal, tricuspidate. Gula distinct, trapezoidal, widest in basal half, length less than maximum width. Antenna three segmented, cylindrical, first segment longer than second.

Thorax. Thoracic tergites light tan, prothoracic sternite anterior to legs light tan to ferruginous, thoracic sternites posterior to prolegs light brown. Prothoracic tergum wider than long, $1.2 \times$ or more length of meso- or metaterga; anterior transverse striated band present, darker than protergal disc; lateral margins with distinct granulated band, darker than protergal disc. Posterior transverse striated band present on all thoracic tergites, unicolorous brown. Meso- and metathoracic tergites wider than long, each with a heavily sclerotized transverse line present on anterior fifth. Thoracic tergites sparsely 
setose on dorsal surfaces, lateral margins more densely setose. Mesothoracic spiracle simple, ovate, approximately $1.5 \times$ size of abdominal spiracles; reduced metathoracic spiracle visible, less than one-fourth size of mesothoracic spiracle. Legs. Prothoracic leg slightly longer, much thicker than meso- and metathoracic legs; prothoracic tarsungulus strongly sclerotized, sickle-shaped; prothoracic trochanter with one or two stout ventromedially spines; prothoracic femur with ventromedial row of six to ten spines, dorsal surface with faintly indicated basal sclerotized band; prothoracic tibia with ventromedial row of eight to eleven spines or spinose setae, dorsal surface slightly more sclerotized than ventral surface. Mesotibia with four to five ventromedial spines.

Abdomen. Abdominal tergites and sternites light tan, with slightly darker transverse striated bands present along posterior margins of segments I-VIII, forming near contiguous unicolorous band around segments. Abdominal sternite I sparsely clothed in long erect setae from anterior margin to near midline. Abdominal laterotergites with lateral margins distinctly pigmented. Abdominal segment IX (pygidium) triangular in dorsal view, gradually reflexed to apex, urogomphi absent, apex forming a distinct tooth, sparsely clothed in short and mid length erect setae, sclerotized uniformly throughout, lacking maculations; marginal row of 17-23 socketed spines present, arranged as single row around posterior two-thirds to one half of segment. Abdominal sternites I-VIII lacking longitudinal tomentose bands along lateral margins. Pygopods short, subconical, each with 9-12 erect setae.

Diagnosis. Eleodes hispilabris larvae can be separated from the other currently known Eleodes species by the presence of an apical tooth on the pygidium, stout spiniform setae on the anterolateral margins of the epipharnyx, and a row of 6-10 ventromedial spines on the prothoracic femur.

\section{Eleodes (Eleodes) tenuipes Casey, 1890}

http://species-id.net/wiki/Eleodes_tenuipes

Material examined. Larval E. tenuipes specimens were reared from adults with the following collecting information: "USA: TX: El Paso County / El Paso, sand dunes off / Hwy 180/Montana Ave. / N31.82327, W106.13234 / 21-22.VIII.2010, ADSmith". Atotal of five eggs and larvae were reared and examined for this study. The following description is based on a detailed examination of one late instar specimen.

Description. Measurements: TL: 39.0 mm, HW: $4.1 \mathrm{~mm}$, PL: $4.0 \mathrm{~mm}$, PW: $4.8 \mathrm{~mm}$.

Head. Prognathous or weakly declined; weakly dorsoventrally flattened; width nearly equal to prothorax; sides rounded; strongly constricted before occipital foramen; color ferruginous, more heavily pigmented than body segments; punctation minute, dense, separated by 1-2 puncture diameters. Epicranial suture stem length approximately onefourth head capsule length; frontal arms sinuate, not obscured by sculpturing. Frons rugose. Epicranial plates rugose dorsally; lateral portions moderately setose; ventral portion of each plate with row of six or more long setae along anterior margin near buccal cavity confluent with setae on lateral portions of plates, and a patch of short setae medially, 
forming a triangular pattern with its base near the anterior margin. Two stemmata present on each epicranial plate, pigmented spots often faded. Clypeus trapezoidal, swollen, darker medially in basal half, minutely punctate, punctation dense, separated by 1-2 puncture diameters. Labrum swollen, sides rounded, basal half more darkly pigmented, medial setal row with six to seven erect setae, subapical setal row with 10-14 erect setae, anterior margin straight to weakly emarginate. Epipharynx anterior setal row with eight or more stout spiniform setae, anterolateral margins with stout spinose setae; six anterior sensory papillae present, arranged in two irregular rows, each with two posterior papillae and one near the anterior margin; four subanterior sensory papillae present, arranged as a transverse row subtended by two spinose setae; eight posterior sensory papillae present, arranged in an irregular cluster. Tormae strongly asymmetric, left torma smaller. Ligula apex lacking microsetae, two long subapical setae present ventrally, eight or more subapical setae present dorsally. Hypopharyngeal sclerome pentagonal, tricuspidate. Gula distinct, trapezoidal, widest in basal half, length less than maximum width. Antenna three segmented, cylindrical, first segment longer than second.

Thorax. Thoracic tergites light tan, prothoracic sternite anterior to legs ferruginous, thoracic sternites posterior to prolegs light brown. Prothoracic tergum wider than long, $1.2 \times$ or more length of meso- or metaterga; anterior transverse striated band present, darker than protergal disc; lateral margins with distinct granulated band, darker than protergal disc. Posterior transverse striated band present on all thoracic tergites, unicolorous brown. Meso- and metathoracic tergites wider than long, each with a heavily sclerotized transverse line present on anterior fifth. Thoracic tergites sparsely setose on dorsal surfaces, lateral margins more densely setose. Mesothoracic spiracle simple, ovate, approximately $1.5 \times$ size of abdominal spiracles; reduced metathoracic spiracle visible, less than one-fourth size of mesothoracic spiracle. Legs. Prothoracic leg slightly longer, much thicker than meso- and metathoracic legs; prothoracic tarsungulus strongly sclerotized, sickle-shaped; prothoracic trochanter with one stout ventromedially spine; prothoracic femur with ventromedial row of 13-14 spines, dorsal surface with faintly indicated basal sclerotized band; prothoracic tibia with ventromedial row of eight to eleven spines or spinose setae, dorsal surface slightly more sclerotized than ventral surface. Mesotibia with five to seven ventromedial spines.

Abdomen. Abdominal tergites and sternites light tan, with slightly darker transverse striated bands present along posterior margins of segments I-VIII, forming near contiguous unicolorous band around segments. Abdominal sternite I sparsely clothed in long erect setae from anterior margin to near midline. Abdominal laterotergites with lateral margins distinctly pigmented. Abdominal segment IX (pygidium) triangular in dorsal view, gradually reflexed to apex, urogomphi absent, apex forming a distinct tooth, sparsely clothed in short and mid length erect setae, sclerotized uniformly throughout, lacking maculations; marginal row of 27 socketed spines present, arranged as single row around posterior two-thirds to one half of segment. Abdominal sternites I-VIII lacking longitudinal tomentose bands along lateral margins.

Diagnosis. Eleodes tenuipes larvae can be separated from the other currently known Eleodes species by the presence of an apical tooth on the pygidium, stout spiniform se- 
tae on the anterolateral margins of the epipharnyx, and a row of 13-14 ventromedial spines on the prothoracic femur. It is further differentiated from E. hispilabris by having a row of three ventromedial spines on the mesotarsus and having the ventral portion of the epicranial plates with a row of six or more long setae along anterior margin near buccal cavity, confluent with setae on lateral portions of plates.

Remarks. Five eggs or early instar larvae were initially placed in a rearing chamber on 25 September 2010, though by the first sifting only one specimen was found. The last specimen thrived until 27 January 2011 when it was preserved for this study.

\section{Eleodes (Eleodes) tribulus Thomas, 2005}

http://species-id.net/wiki/Eleodes_tribulus

Figures 2D, 5B, 9D

Material examined. Larval E. tribulus specimens were reared from adults with the following collecting information: "USA: AZ: Pinal Co. / I-10W Rest Area, mm183 / 33.029288, -111.771716 / 02 May 2011, ADSmith”. A total of 824 eggs and larvae were reared and examined for this study, of which 134 survived until the 2 nd instar or later. The following description is based on a detailed examination of ten 8-11th instar specimens.

Description. TL: $13.0-19.0 \mathrm{~mm}, \mathrm{HW}: 1.5-2.2 \mathrm{~mm}$, PL: $1.2-2.7 \mathrm{~mm}$, PW: $1.3-2.7 \mathrm{~mm}$.

Head. Prognathous or weakly declined; weakly dorsoventrally flattened; width nearly equal to prothorax; sides angular; strongly constricted before occipital foramen; color light tan to medium brown, more heavily pigmented than body segments ; punctation minute, moderately dense, separated by $2-4$ puncture diameters. Epicranial suture stem length approximately one-third head capsule length; frontal arms sinuate, not obscured by sculpturing. Frons rugose. Epicranial plates weakly rugose dorsally; lateral portions moderately setose; ventral portion of each plate with row of six or more long setae along anterior margin near buccal cavity confluent with setae on lateral portions of plates, and a patch of short setae medially, forming a triangular pattern with its base near the anterior margin. Two stemmata present on each epicranial plate, pigmented spots often faded. Clypeus trapezoidal, swollen, darker medially in basal half, minutely punctate, punctation moderately dense, separated by $2-4$ puncture diameters. Labrum swollen, sides rounded, basal half more darkly pigmented, medial setal row with six to seven erect setae subapical setal row with six to seven erect setae, anterior margin straight to weakly emarginate. Epipharynx (Fig. 9D) anterior setal row with six stout spiniform setae, anterolateral margins with micro-setation; five to six anterior sensory papillae present, arranged in two irregular longitudinal rows or an irregular cluster; four subanterior sensory papillae present, arranged as a transverse row subtended by two spinose setae; seven to eight posterior sensory papillae present, arranged in an irregular cluster. Tormae asymmetric, left torma larger. Ligula apex and subapical dorsal surface densely micro-setose, two long subapical setae present ventrally. Hypopharyngeal sclerome pentagonal, tricuspidate. Gula distinct, trapezoidal, 
widest in basal half, length subequal or greater than maximum width. Antenna three segmented, cylindrical, first segment length subequal to second.

Thorax. Thoracic tergites light tan, prothoracic sternite anterior to legs medium brown, thoracic sternites posterior to prolegs light brown. Prothoracic tergum subquadrate, $1.5 \times$ length of meso- or metaterga; lateral margins with distinct granulated band, darker than protergal disc; anterior transverse striated band present, darker than tergal disc. Posterior transverse striated band present on all thoracic tergites, unicolorous brown. Meso- and metathoracic tergites wider than long, each with a faintly indicated sclerotized transverse line present on anterior fifth. Thoracic tergites sparsely setose on dorsal surfaces, lateral margins more densely setose. Mesothoracic spiracle simple, ovate, approximately $1.5 \times$ size of abdominal spiracles; reduced metathoracic spiracle visible, less than one-fourth size of mesothoracic spiracle. Legs. Prothoracic leg slightly longer, much thicker than meso- and metathoracic legs; prothoracic tarsungulus strongly sclerotized, sickle-shaped; prothoracic trochanter with two stout spines ventromedially; prothoracic femur with ventromedial row of two spines and three to five longer setae, dorsal surface with faintly indicated basal sclerotized band; prothoracic tibia with ventromedial row of three to four spines, dorsal surface slightly more sclerotized than ventral surface. Mesotibia with three ventromedial spines.

Abdomen. Abdominal tergites and sternites light tan with darker transverse striated bands present along posterior margins of segments I-VIII, forming near contiguous unicolorous band around segments. Abdominal sternite I moderately clothed in long erect setae from anterior margin to near midline. Abdominal laterotergites with lateral margins distinctly pigmented. Abdominal segment IX (pygidium) triangular in dorsal view, gradually reflexed to apex, urogomphi absent, apex not forming a distinct tooth, moderately clothed in short and mid length erect setae, sclerotized uniformly throughout, lacking maculations; marginal row of 8-14 socketed spines present, arranged as single row around posterior two-thirds to one half of segment. Abdominal sternites I-VIII lacking longitudinal tomentose bands along lateral margins. Pygopods short, subconical, each with 11-15 erect setae.

Diagnosis. Eleodes tribulus larvae can be separated from the other currently known Eleodes species based on the pentagonal hypopharyngeal sclerome, lack of a caudal tooth on the pygidium, presence of 8-14 marginal spines on the pygidium, and the angular, nearly straight sides of the head capsule.

\section{Subgenus Litheleodes Blaisdell, 1909}

Eleodes (Litheleodes) extricatus (Say, 1823)

http://species-id.net/wiki/Eleodes_extricatus

Figures 3A, 5C, 7B, 10A, 12B, 13B

Material examined. Larval E. extricatus specimens were reared from adults with the following collecting information: "USA: TX: El Paso County / El Paso, sand dunes 
off / Hwy 180/Montana Ave. / N31.82327, W106.13234 / 21-22.VIII.2010, ADSmith", "USA: Arizona: Navajo Co. / dunes $-4 \mathrm{mi}$ N Chilchinbito / off route 59, el. 1738m / N36.58143, W110.06973 / 26.August.2010, ADSmith", "USA: AZ: Graham Co. / Pinaleño Mnts, Hospital Flat Camp / N32³9’58.0”, W10952’30.9” / el.9000' 22.Aug.2010 / ADSmith", "USA: Arizona: Gila County / E. Verde River off NF-272 / N34.303, W111.3496 / 27.August.2010, ADSmith". Approximately 219 eggs and larvae were reared and examined for this study, with 150 surviving until the second instar or beyond. The following description is based on a detailed examination of thirteen 8-11th instar specimens.

Description. Measurements: TL: 15.4-33.3 mm, PL: 2.4-3.8 mm, PW: 2.2-3.8 mm, HW: 2.0-3.0 mm.

Head. Prognathous or weakly declined; weakly dorsoventrally flattened; width nearly equal to prothorax; sides rounded; strongly constricted before occipital foramen; color light tan, same or nearly the same as body segments; punctation minute, dense, separated by 1-2 puncture diameters. Epicranial suture stem length approximately one-third head capsule length; frontal arms sinuate, not obscured by sculpturing. Frons faintly rugose. Epicranial plates faintly rugose dorsally; lateral portions moderately setose; ventral portion of each plate with row of six or more long setae along anterior margin near buccal cavity confluent with setae on lateral portions of plates and a patch of short setae medially, forming a triangular pattern with its base near the anterior margin. Two stemmata present on each epicranial plate, pigmented spots often faded. Clypeus trapezoidal, swollen or not, unicolorous, minutely punctate, punctation dense, separated by 1-2 puncture diameters. Labrum swollen, sides rounded, basal half more darkly pigmented, medial setal row with six to seven erect setae, subapical setal row with six to seven erect setae, anterior margin straight to weakly emarginate. Epipharynx (Fig. 10A) anterior setal row with six stout spiniform setae, anterolateral margins with micro-setation; six anterior sensory papillae present, arranged in two irregular rows; four subanterior sensory papillae present, arranged as a transverse row subtended by two spinose setae; eight posterior sensory papillae present, arranged in an irregular cluster. Tormae symmetrical or weakly asymmetrical with left torma smaller. Ligula apex densely microsetose, two long subapical setae present ventrally. Hypopharyngeal sclerome pentagonal, tricuspidate. Gula distinct, trapezoidal, widest in basal half, length less than maximum width. Antenna three segmented, cylindrical, first segment longer than second.

Thorax. Thoracic tergites light tan, prothoracic sternite anterior to legs ferruginous, thoracic sternites posterior to prolegs light brown. Prothoracic tergum subquadrate, $1.5 \times$ length of meso- or metaterga; anterior transverse striated band present, darker than protergal disc; lateral margins with distinct granulated band, darker than protergal disc. Posterior transverse striated band present on all thoracic tergites, unicolorous brown. Meso- and metathoracic tergites wider than long, each with a heavily sclerotized transverse line present on anterior fifth. Thoracic tergites sparsely setose on dorsal surfaces, lateral margins more densely setose. Mesothoracic spiracle simple, ovate, approximately $1.5 \times$ size of abdominal spiracles; reduced metathoracic spiracle visible, 
less than one-fourth size of mesothoracic spiracle. Legs. Prothoracic leg slightly longer, much thicker than meso- and metathoracic legs; prothoracic tarsungulus strongly sclerotized, sickle-shaped; prothoracic trochanter with two stout ventromedially spines; prothoracic femur with ventromedial row of two spines and three to five longer setae, dorsal surface with faintly indicated basal sclerotized band; prothoracic tibia with ventromedial row of three to four spines or spinose setae, dorsal surface slightly more sclerotized than ventral surface. Mesotibia with four to five ventromedial spines.

Abdomen. Abdominal tergites and sternites light tan, with slightly darker transverse striated bands present along posterior margins of segments I-VIII, forming near contiguous unicolorous band around segments. Abdominal sternite I sparsely clothed in long erect setae from anterior margin to near midline. Abdominal laterotergites with lateral margins distinctly pigmented. Abdominal segment IX (pygidium) triangular in dorsal view, gradually reflexed to apex, urogomphi absent, apex lacking a distinct tooth, sparsely clothed in short and mid length erect setae, sclerotized uniformly throughout, lacking maculations; marginal row of 17-23 socketed spines present, arranged as single row around posterior two-thirds to one half of segment. Abdominal sternites I-VIII lacking longitudinal tomentose bands along lateral margins. Pygopods short, subconical, each with 11-15 erect setae.

Diagnosis. Eleodes extricatus larvae can be separated from the other currently known Eleodes species based on the pentagonal hypopharyngeal sclerome, small or absent apical tooth on the pygidium, lateral margins of prothoracic tergum with a distinct granulated band, and having antennal segment I longer than antennal segment II.

Remarks. Eleodes extricatus is a widespread species found on dunes and at high elevations. Specimens from Arizona and Texas showed no population differences in the larval stage. Adults varied in the presence or prominence of muricate tubercles on the elytra.

\section{Subgenus Melaneleodes Blaisdell, 1909}

\section{Eleodes (Melaneleodes) anthracinus Blaisdell, 1909}

http://species-id.net/wiki/Eleodes_anthracinus

Figures 3B, 6A, 7A, 8

Material examined. Larval E. anthracinus specimens were reared from adults with the following collecting information: "USA: AZ: Maricopa Co. / Eugie Ave \& 7th St. / 25 Oct. 2011, R. Dornburg." A total of 28 eggs and larvae were reared and examined for this study, of which all survived until the 3rd instar or later. The following description is based on a detailed examination of four 8-11th instar specimens.

Description. TL: $23.8-28.1 \mathrm{~mm}, \mathrm{HW}: 2.3-2.4 \mathrm{~mm}, \mathrm{PL}: 2.0-2.4 \mathrm{~mm}$, PW: $2.5-2.8 \mathrm{~mm}$.

Head. Prognathous or weakly declined; weakly dorsoventrally flattened; width nearly equal to prothorax; sides rounded; strongly constricted before occipital fo- 


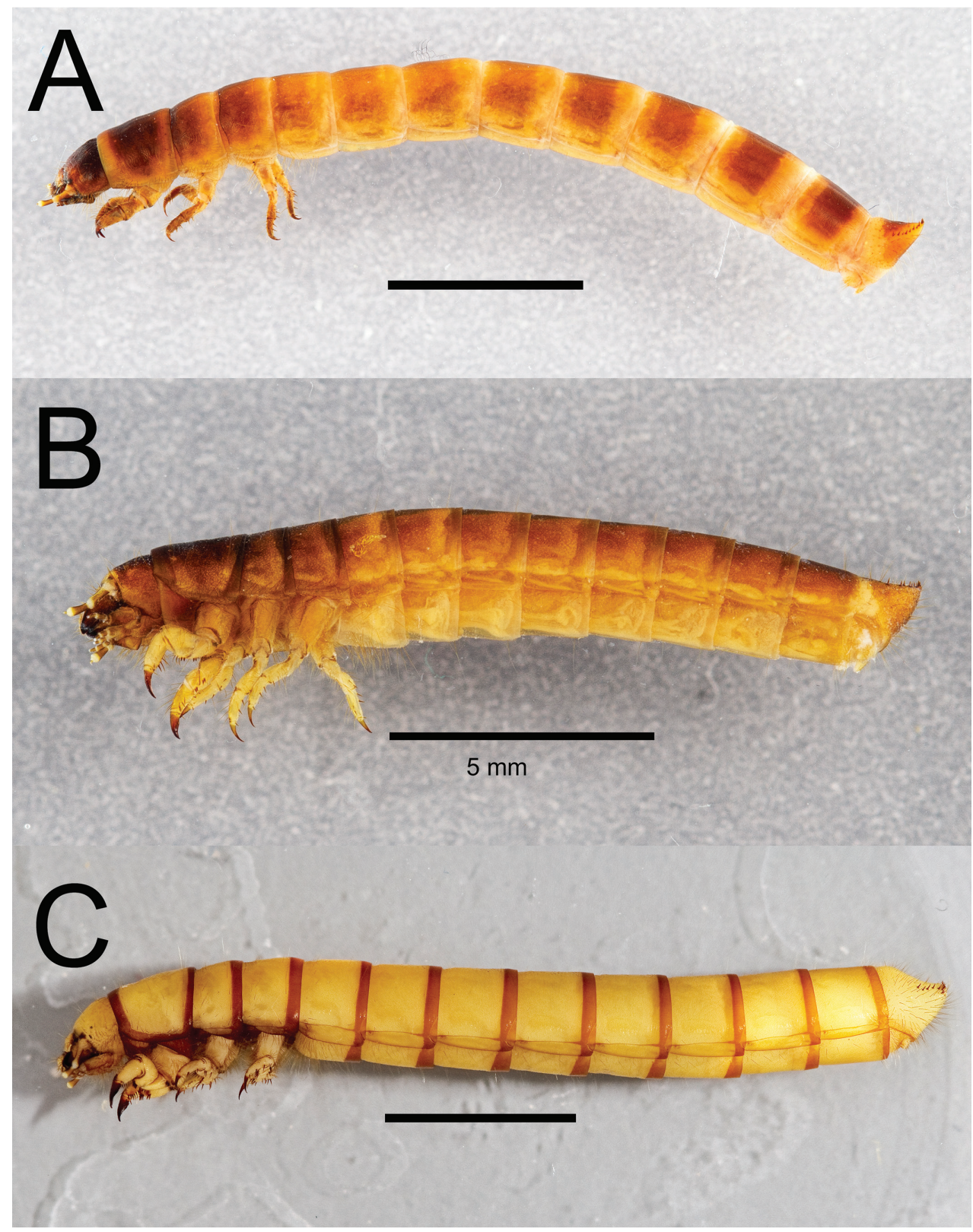

Figure 6. Lateral habitus of three Eleodes species: A E. (Melaneleodes) anthracinus B E. (Melaneleodes) carbonarius $\mathbf{C}$. (Tricheleodes) pilosus. Scale bar $=5 \mathrm{~mm}$.

ramen; color medium brown to brown-grey, nearly as on body segments; minute punctation moderately dense dorsally. Epicranial stem approximately one-third head capsule length; frontal arms U-shaped, not obscured by sculpturing. Frons and dorsal portion of epicranial plates faintly rugose; lacking non-primary setae. 


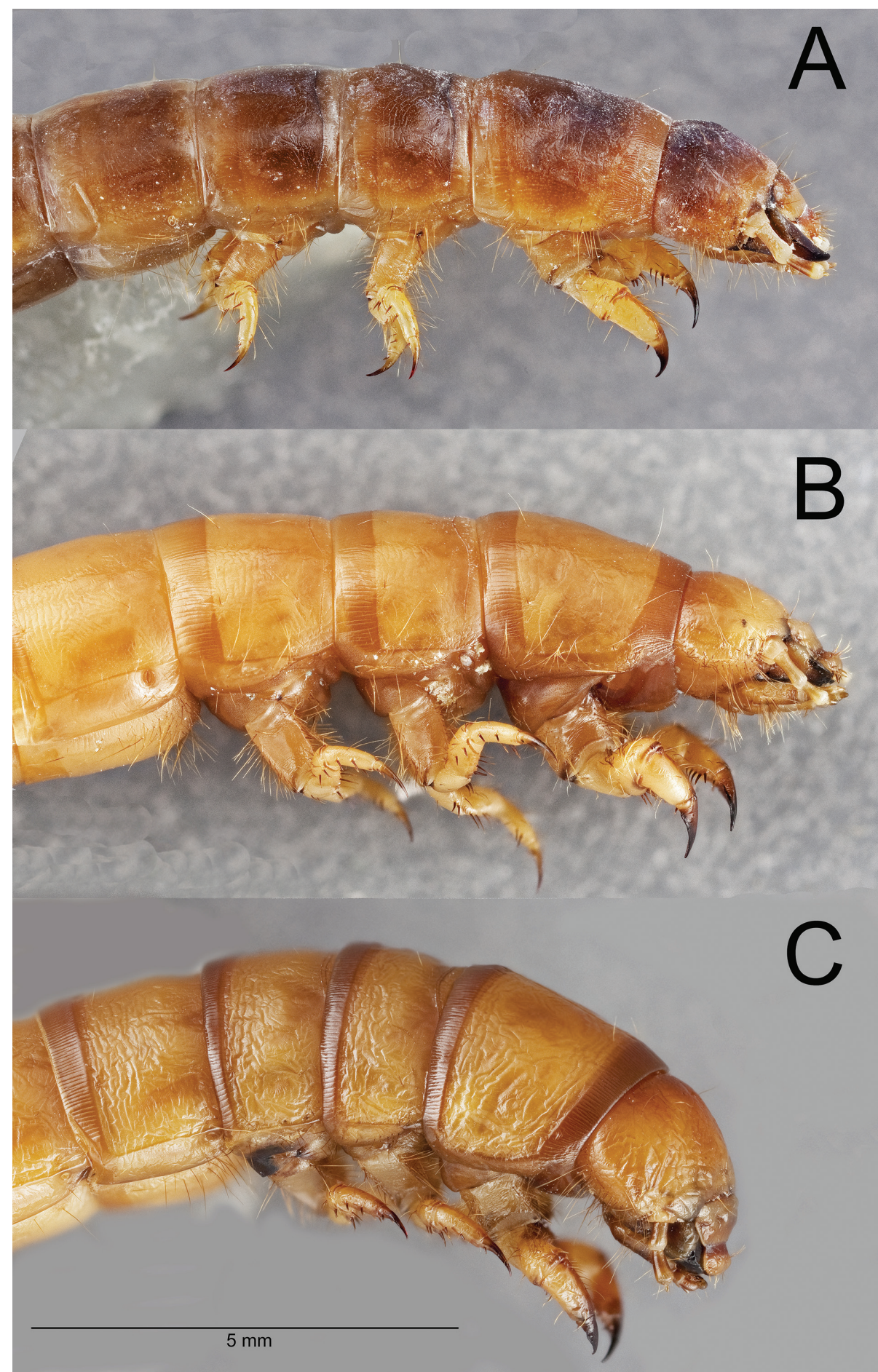

Figure 7. Lateral habitus of the head and thoracic segments of three Eleodes species: A E. (Melaneleodes) anthracinus $\mathbf{B}$ E. (Litheleodes) extricatus $\mathbf{C}$ E. (Promus) subnitens. Scale bar $=5 \mathrm{~mm}$. 
Lateral portions of epicranial plates moderately setose; setae golden, erect, length equal to or longer than antennal segment 2 ; ventral portions of epicranial plates with a row of four long setae along anterior margin near buccal cavity with a patch of short setae medially forming a triangular pattern with its base near the anterior margin; two stemmata present on each plate, pigmented spots often faded. Clypeus trapezoidal; not swollen, moderately punctate, darker medially in basal half. Labrum not swollen, basal half more darkly pigmented; sides rounded; two transverse rows of seven to eight erect setae present medially and subapically; anterior margin straight. Epipharynx (Fig. 3) anterior setal row with six stout spiniform setae, anterolateral margins with micro-setation; six anterior sensory papillae present, arranged in two irregular diagonal rows; four subanterior sensory papillae present, arranged as a transverse row subtended by two spinose setae; eight posterior sensory papillae present, arranged in two irregular rows.Tormae asymmetrical, left torma smaller. Ligula with four long setae near apex. Hypopharyngeal sclerome trapezoidal. Gula distinct, trapezoidal, widest in basal half. Antenna three segmented, cylindrical; first segment longer than second.

Thorax. Grey-brown to medium brown dorsally and anterior to legs on prothoracic sternite, tan on rest of sternites; lighter transverse striated band present along anterior fourth of prothoracic tergum; thin darkly sclerotized transverse line present on anterior fifth of meso- and metathoracic tergites; striated bands present along posterior 5 th of all thoracic tergites, color forming a gradient from darker brown anteriorly to lighter brown along posterior border. Eight evenly arranged setae present on dorsal surface of each thoracic terga, lateral margins more densely setose. Prothoracic tergum subquadrate, $1.5 \times$ length of meso- or metaterga; lateral margins lacking pigmented band. Meso- and metaterga wider than long, lacking pigmented bands along lateral margins; mesothoracic spiracle simple, ovate, approximately $1.5 \times$ size of abdominal spiracle; reduced metathoracic spiracle visible, less than one-fourth size of mesothoracic spiracle. Prothoracic leg slightly longer, much thicker than meso- and metathoracic legs; prothoracic tarsungulus strongly sclerotized, sickle-shaped; trochanter with row of two stout spines and two longer setae ventromedially, tibia with ventromedial row of two spines and four to five longer setae, tarsus with ventromedial row of four spines. Dorsal surface of protibia (at rest) with faintly indicated basal sclerotized band; dorsal surface of protarsus slightly more sclerotized than ventral surface.

Abdomen. Tergites grey-brown to medium brown dorsally, lightening towards lateral margins, sternites light to dark tan; transverse striated bands not visible on abdominal sternites, barely visible on posterior 5 th of terga I-VIII, nearly concolorous with rest of tergites. Abdominal sternite I sparsely clothed in long erect setae from anterior margin to near midline, abdominal segments II-VIII each with two sparse transverse bands of long erect setae, posterior margin of segment 8 denser setal band. Abdominal laterotergites concolorous with tergites, lacking distinct pigmented margins. Abdominal segment IX (pygidium) triangular in dorsal view, gradually reflexed to apex, sparsely clothed in short and mid length erect setae, dorsally more sclerotized in apical two-thirds with faint maculations; marginal row of 14-18 socketed spines 


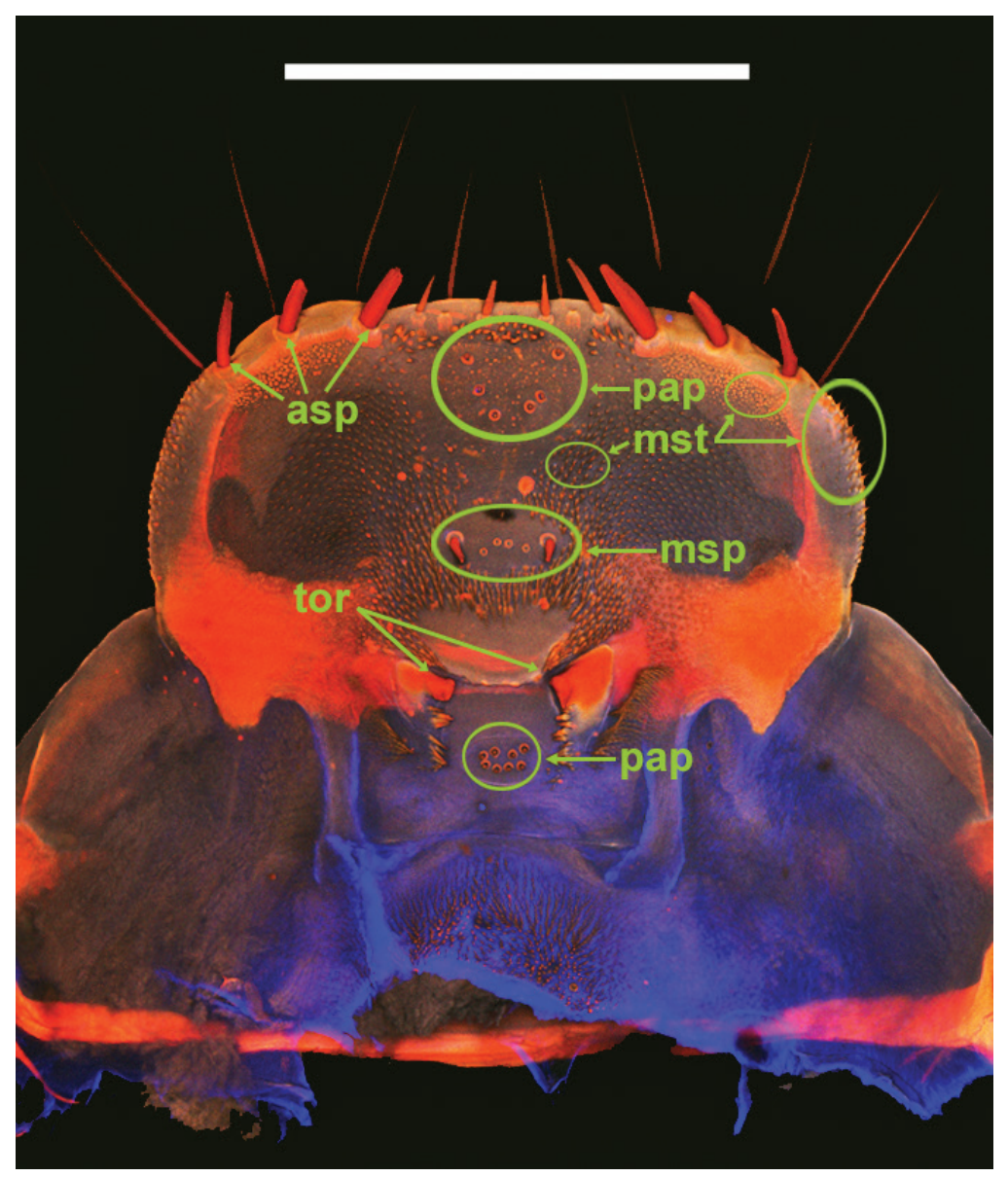

Figure 8. Eleodes (Melaneleodes) anthracinus, epipharnyx. asp = anterior spines, $\mathrm{msp}=$ medial spines, $\mathrm{mst}$ $=$ microsetae, pap $=$ sensory papillae, tor $=$ tormae. Scale bar $=1 \mathrm{~mm}$.

present apical half, apex not forming distinct sclerotized projection. Pygopods short, subconical, each with $11-15$ erect spines.

Variation. Little variation was observed between specimens beyond the number of spines on the legs and pygidium, and the overall degree of sclerotization.

Diagnosis. Eleodes anthracinus larvae can be separated from most currently known Eleodes species based on their darker dorsal coloration on all segments, the absence of pigmented bands along the lateral margins of the thoracic terga, and the lack of a distinct sclerotized tooth at the apex of the pygidium. They can be distinguished from E. carbonarius larvae by their lighter ventral segments and lack of distinct posterior pigmented bands on the abdominal terga. Larvae of Eleodes tricostatus (Say), another species in the subgenus Melaneleodes, are mentioned as being "nearly black" by McColloch (1918). However, no other diagnostic characters are mentioned that would separate them from the other E. anthracinus or E. carbonarius. 


\section{Eleodes (Melaneleodes) carbonarius knausii Blaisdell}

Figures 3C, 6B, 9A, 11A, 12A

Material examined. Larval E. carbonarius specimens were reared from adults with the following collecting information: "USA: CO: Montezuma Co. / Ute RA off Hwy 160 / 37.3535, -108.44385 / 05 Jun 2011, ADSmith”. A total of 129 eggs and larvae were reared and examined for this study, with 45 surviving until the 2 nd instar or later. The following description is based on a detailed examination of five 8-11th instar specimens.

Description. TL: $15.5-26 \mathrm{~mm}$, HW: 2.3-3.0 mm, PL: 1.9-2.5 mm, PW: 3.0$3.5 \mathrm{~mm}$.

Head. Prognathous, weakly flattened, narrower than prothorax; sides rounded, strongly constricted before occipital foramen; color ferruginous to dark brown, nearly as on body segments; minute punctation moderately dense dorsally. Epicranial stem approximately one-third head capsule length; frontal arms U-shaped, not obscured by sculpturing. Frons and dorsal portion of epicranial plates faintly rugose; lacking nonprimary setae. Lateral portions of epicranial plates moderately setose; setae golden, erect, length equal to or longer than antennal segment 2; ventral portions of epicranial plates with a row of four to five long setae along anterior margin near buccal cavity and a patch of short setae medially forming a triangular pattern with its base near the anterior margin; two stemmata present on each plate, pigmented spots often faded. Clypeus trapezoidal; not swollen, moderately punctate, darker medially in basal half. Labrum not swollen, basal half more darkly pigmented; sides rounded; two transverse rows of six to seven erect setae present medially and subapically; anterior margin straight to weakly emarginate. Epipharynx (Fig. 9A) anterior setal row with six stout spiniform setae, anterolateral margins with micro-setation; six anterior sensory papillae present, arranged in two irregular diagonal rows; four subanterior sensory papillae present, arranged as a transverse row subtended by two spinose setae; eight posterior sensory papillae present, arranged in an irregular cluster. Tormae asymmetrical, left torma larger. Hypopharyngeal sclerome trapezoidal. Ligula with four long setae near apex. Gula distinct, trapezoidal, widest in basal half. Antenna three segmented, cylindrical; first segment longer than second.

Thorax. Dark brown to ferruginous dorsally and anterior to legs on prothoracic sternite, lighter brown on rest of sternites; distinct longitudinally striated band present along anterior fourth of prothoracic tergum; thin darkly sclerotized transverse line present on anterior fifth of meso- and metathoracic tergites; striated bands present along posterior 6th of all thoracic tergites, darker than rest of surface. Eight evenly arranged setae present on dorsal surface of each thoracic terga, lateral margins more densely setose. Prothoracic tergum wider than long, $1.5 \times$ length of meso- or metaterga; lateral margins lacking pigmented band. Meso- and metaterga wider than long, lacking pigmented bands along lateral margins; mesothoracic spiracle simple, ovate, approximately $1.5 \times$ size of abdominal spiracle; reduced metathoracic spiracle visible, less than one-fourth size of mesothoracic spiracle. Prothoracic leg slightly longer, much thicker than meso- and metathoracic legs; prothoracic tarsungulus strongly sclerotized, sickle- 


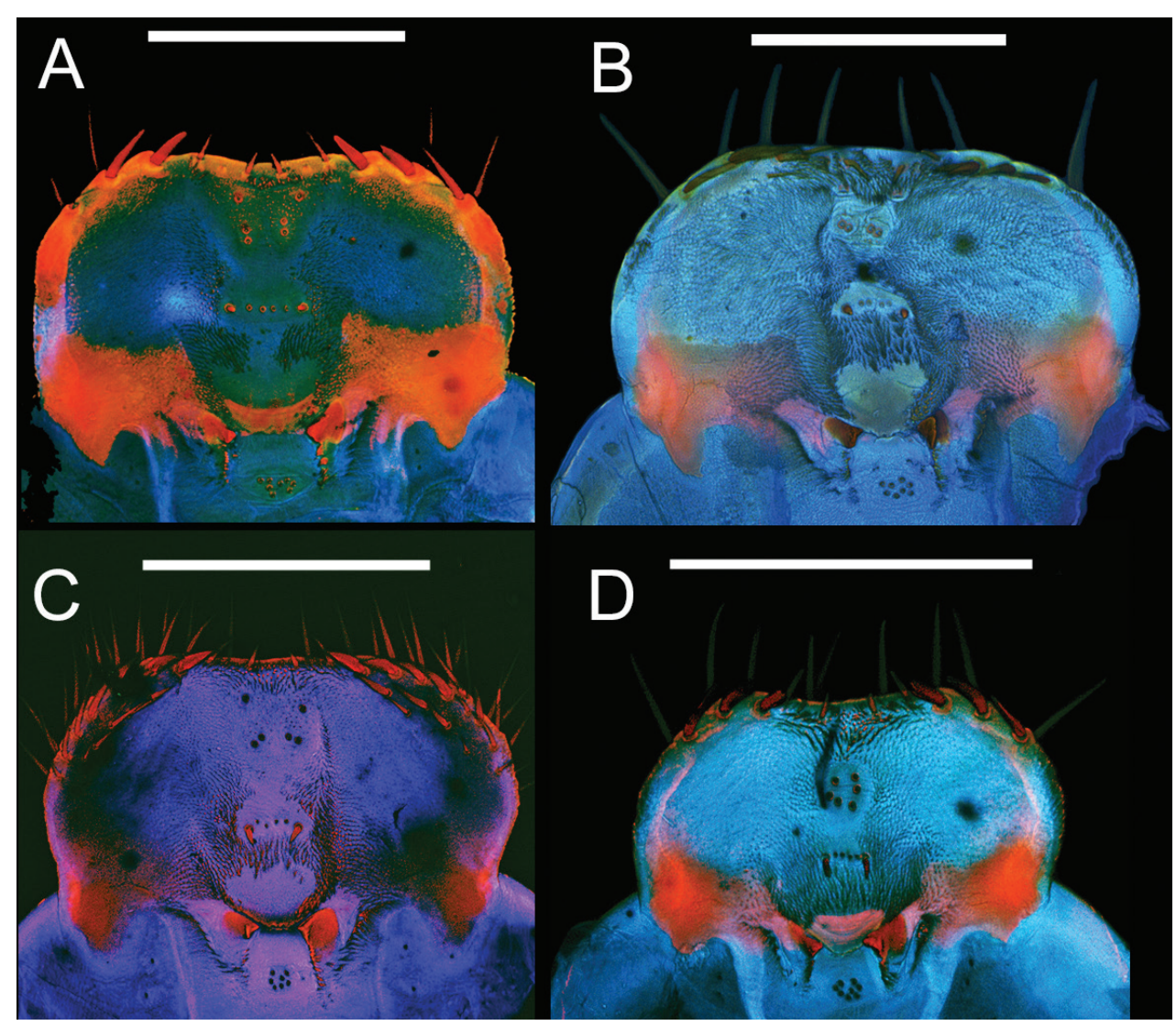

Figure 9. Epipharynges of four Eleodes species: A E. (Melaneleodes) carbonarius B E. (Eleodes) armatus C E. (Eleodes) hispilabris $\mathbf{D}$ E. (Eleodes) tribulus. Scale bars $=1 \mathrm{~mm}$.

shaped; trochanter with two stout spines ventromedially, tibia with ventromedial row of three to four spines and four to five longer setae, tarsus with ventromedial row of five spines. Dorsal surface of protibia (at rest) with basal sclerotized band; dorsal surface of protarsus more sclerotized than ventral surface.

Abdomen. Tergites dark brown to ferruginous, concolorous or lightly lighter than tergites; longitudinally striated bands not visible on abdominal sternites, distinct on posterior 5 th of terga $1-8$. Abdominal sternite I sparsely clothed in long erect setae from anterior margin to near midline, abdominal segments $2-8$ each with two sparse transverse bands of long erect setae, posterior margin of segment 8 denser setal band. Abdominal laterotergites concolorous with tergites, lacking distinct pigmented margins. Abdominal segment IX (pygidium) triangular in dorsal view, gradually reflexed to apex, sparsely clothed in short and mid length erect setae, apical two-thirds with faint maculations; marginal row of 18-20 socketed spines present apical half, apex not forming distinct sclerotized projection. Pygopods short, subconical, each with $9-12$ erect spines. 
Variation. Little variation was observed between specimens beyond the number of spines on the legs and pygidium, and the overall degree of sclerotization.

Diagnosis. Eleodes carbonarius larvae can be separated from most currently known Eleodes species their darker dorsal coloration on all segments, the absence of pigmented bands along the lateral margins of the thoracic terga, and the lack of a distinct sclerotized tooth at the apex of the pygidium. They can be further distinguished from $E$. anthracinus larvae as outlined in that species diagnosis.

Remarks. Eleodes carbonarius adult morphology is notoriously variable across the species range and even within populations. Nine subspecies are currently recognized (Triplehorn and Thomas 2011). The specimens examined were all reared from a few females of E. carbonarius knausi Blaisdell collected at a single locality. Larval characters showed little variation; however, this may change as more specimens are reared from other localities and subspecies.

\section{Subgenus Promus LeConte, 1862}

\section{Eleodes (Promus) goryi Solier, 1848}

http://species-id.net/wiki/Eleodes_goryi

Figures 10B, 11C

Material examined. Larval E. goryi specimens were reared from adults with the following collecting information: "USA: TX: Hidalgo County / Bentsen-Rio Grande Valley / State Park, fm2062 Mission / N26⒑37’, W098²2.93’ / 02.Sept.2011, Aaron Smith". A total of 460 eggs and larvae were reared and examined for this study, with 25 surviving until the 2 nd instar or beyond. The following description is based on a detailed examination of three $8-11$ th instar specimens.

Description. TL: $25.0-25.4 \mathrm{~mm}$, HW: $2.0-2.1 \mathrm{~mm}$, PL: $2.0-2.1 \mathrm{~mm}$, PW:

\section{2-2.4 mm.}

Head. Prognathous or weakly declined; weakly dorsoventrally flattened; width nearly equal to prothorax; sides rounded; strongly constricted before occipital foramen; color ferruginous to dark brown, more heavily pigmented than body segments; punctation minute, moderately dense, separated by $2-4$ puncture diameters. Epicranial suture stem length approximately one-third head capsule length; frontal arms U-shaped, not obscured by sculpturing. Frons faintly rugose. Epicranial plates faintly rugose dorsally; lateral portions moderately setose; ventral portion of each plate with row of six or more long setae along anterior margin near buccal cavity confluent with setae on lateral portions of plates, and a patch of short setae medially, forming a triangular pattern with its base near the anterior margin. Two stemmata present on each epicranial plate, pigmented spots often faded. Clypeus trapezoidal, swollen, darker medially in basal half, minutely punctate, punctation moderately dense, separated by 2-4 puncture diameters. Labrum swollen, sides rounded, basal half more darkly pigmented, medial setal row with six to seven erect setae, subapical setal row with six 


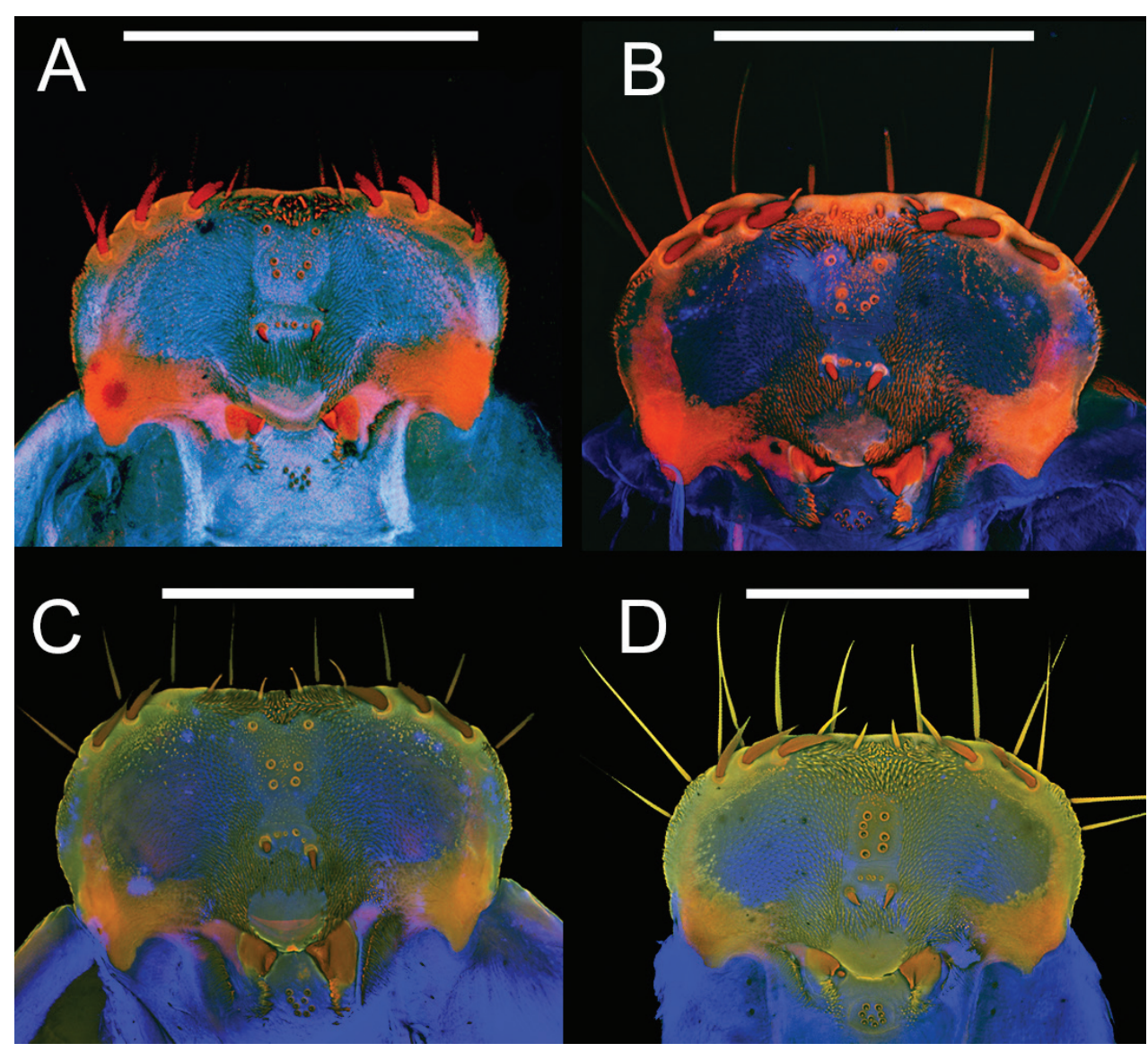

Figure 10. Epipharynges of four Eleodes species: A E. (Litheleodes) extricatus B E. (Promus) goryi $\mathbf{C}$ E. (Promus) subnitens $\mathbf{D}$ E. (Tricheleodes) pilosus. Scale bars $=1 \mathrm{~mm}$.

to seven erect setae, anterior margin straight to weakly emarginate. Epipharynx (Fig. 10B) anterior setal row with six stout spiniform setae, anterolateral margins with micro-setation; six anterior sensory papillae present, arranged in two irregular rows; four subanterior sensory papillae present, arranged as a transverse row subtended by two spinose setae; eight posterior sensory papillae present, arranged in an irregular cluster. Tormae strongly asymetrical with left torma larger. Ligula apex densely microsetose, two long subapical setae present ventrally. Hypopharyngeal sclerome pentagonal, tricuspidate. Gula distinct, trapezoidal, widest in basal half, length subequal or greater than maximum width. Antenna three segmented, cylindrical, first segment subequal to second.

Thorax. Thoracic tergites light tan, prothoracic sternite anterior to legs ferruginous to medium brown, thoracic sternites posterior to prolegs medium brown. Prothoracic tergum wider than long, $1.2 \times$ or more length of meso- or metaterga; anterior transverse striated band present, darker than protergal disc; lateral margins with distinct 
granulated band, darker than protergal disc. Posterior transverse striated band present on all thoracic tergites, unicolorous brown. Meso- and metathoracic tergites wider than long, each with a heavily sclerotized transverse line present on anterior fifth. Thoracic tergites sparsely setose on dorsal surfaces, lateral margins more densely setose. Mesothoracic spiracle simple, ovate, approximately $1.5 \times$ size of abdominal spiracles; reduced metathoracic spiracle visible, less than one-fourth size of mesothoracic spiracle. Legs. Prothoracic leg slightly longer, much thicker than meso- and metathoracic legs; prothoracic tarsungulus strongly sclerotized, sickle-shaped; prothoracic trochanter with two stout ventromedially spines; prothoracic femur with ventromedial row of two spines and three to five longer setae, dorsal surface with faintly indicated basal sclerotized band; prothoracic tibia with ventromedial row of three to four spines or spinose setae, dorsal surface slightly more sclerotized than ventral surface. Mesotibia with three ventromedial spines.

Abdomen. Abdominal tergites and sternites 1-7 light tan, with slightly darker transverse striated bands present along posterior margins of segments I-VIII, forming near contiguous unicolorous band around segments. Abdominal tergite 8 more darkly pigmented than preceding segments. Abdominal sternite I moderately clothed in long erect setae from anterior margin to near midline. Abdominal laterotergites with lateral margins distinctly pigmented. Abdominal segment IX (pygidium) triangular in dorsal view, gradually reflexed to apex, urogomphi absent, apex lacking a distinct tooth, moderately clothed in short and mid length erect setae, dorsally more sclerotized in apical two-thirds with faint maculations; marginal row of 18-20 socketed spines present, arranged as single row around posterior two-thirds to one half of segment. Abdominal sternites I-VIII lacking longitudinal tomentose bands along lateral margins. Pygopods short, subconical, each with 11-15 erect setae.

Diagnosis. Eleodes goryi larvae can be separated from the other currently known Eleodes species based on the darkly pigmented eighth and ninth abdominal tergites. It is further distinguished by the pentagonal hypopharyngeal sclerome, lack of a caudal tooth on the pygidium, and the presence of 3-4 ventromedial spines on the protibia.

\section{Eleodes (Promus) subnitens LeConte, 1851}

http://species-id.net/wiki/Eleodes_subnitens

Figures $7 \mathrm{C}, 10 \mathrm{C}$

Material examined. Larval E. subnitens specimens were reared from adults with the following collecting information: "USA: Arizona: Gila Co. / Tonto Natural Bridge SP / N34.3214, W111.4569 / 11.IX.2010, ADSmith". A total of 7 eggs and larvae were reared and examined for this study, of which four survived until the 2 nd instar or later. The following description is based on a detailed examination of two 8-11th instar specimens.

Description. TL: $23.1-30.8 \mathrm{~mm}$, HW: $2.0-3.0 \mathrm{~mm}$, PL: $2.0-2.9 \mathrm{~mm}$, PW: 2.2-3.1 mm. 


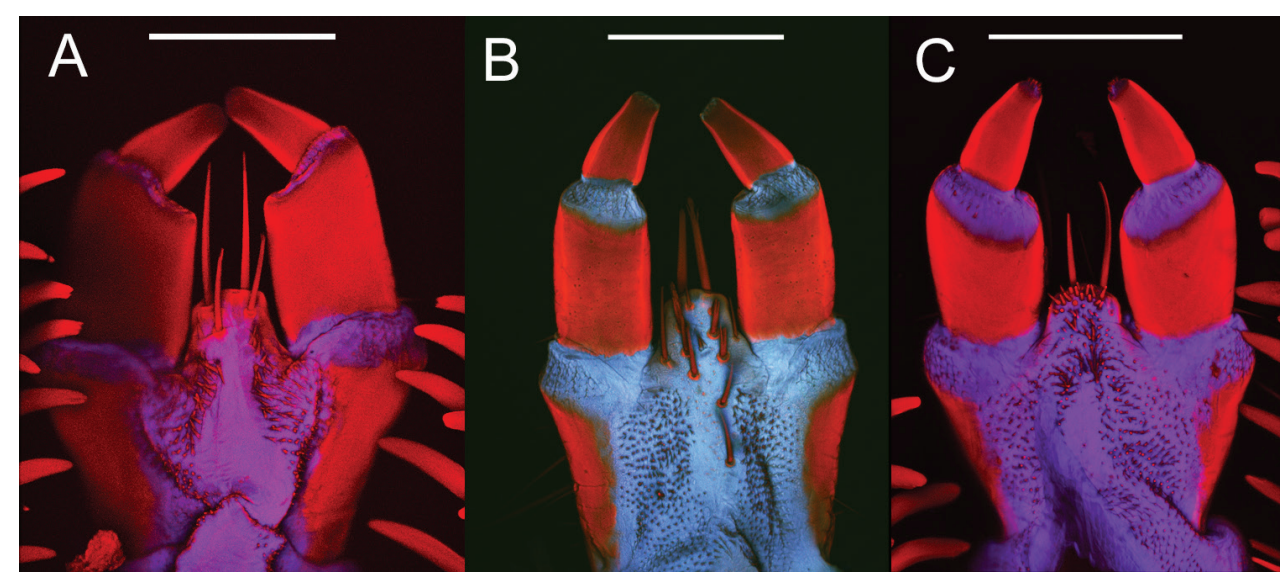

Figure II. Ligulas of three Eleodes species: A E. (Melaneleodes) carbonarius $\mathbf{B}$ E. (Eleodes) armatus $\mathbf{C} E$. (Promus) goryi. Scale bars $=200 \mu \mathrm{m}$.

Head. Prognathous or weakly declined; weakly dorsoventrally flattened; width nearly equal to prothorax; sides rounded; strongly constricted before occipital foramen; color ferruginous, more heavily pigmented than body segments; punctation minute, moderately dense, separated by $2-4$ puncture diameters. Epicranial suture stem length approximately one-third head capsule length; frontal arms sinuate, not obscured by sculpturing. Frons faintly rugose. Epicranial plates faintly rugose dorsally; lateral portions moderately setose; ventral portion of each plate with row of six or more long setae along anterior margin near buccal cavity confluent with setae on lateral portions of plates and a patch of short setae medially, forming a triangular pattern with its base near the anterior margin. Two stemmata present on each epicranial plate, pigmented spots often faded. Clypeus trapezoidal, swollen, darker in apical half, minutely punctate, punctation moderately dense, separated by $2-4$ puncture diameters. Labrum swollen, sides rounded, basal half more darkly pigmented, medial setal row with six to seven erect setae, subapical setal row with seven to eight erect setae, anterior margin straight to weakly emarginate. Epipharynx (Fig. 10C) anterior setal row with six stout spiniform setae, anterolateral margins with micro-setation; six anterior sensory papillae present, arranged in two irregular rows; four subanterior sensory papillae present, arranged as a transverse row subtended by two spinose setae; eight posterior sensory papillae present, arranged in an irregular cluster. Tormae asymetrical with left torma smaller. Ligula apex densely microsetose, two long subapical setae present ventrally. Hypopharyngeal sclerome pentagonal, tricuspidate. Gula distinct, trapezoidal, widest in basal half, length subequal or greater than maximum width. Antenna three segmented, cylindrical, first segment subequal to second.

Thorax. Thoracic tergites light tan, prothoracic sternite anterior to legs ferruginous, thoracic sternites posterior to prolegs light brown. Prothoracic tergum wider than long, $1.2 \times$ or more length of meso- or metaterga; anterior transverse striated band present, darker than protergal disc; lateral margins with distinct granulated band, darker than protergal disc. Posterior transverse striated band present on all thoracic tergites, uni- 


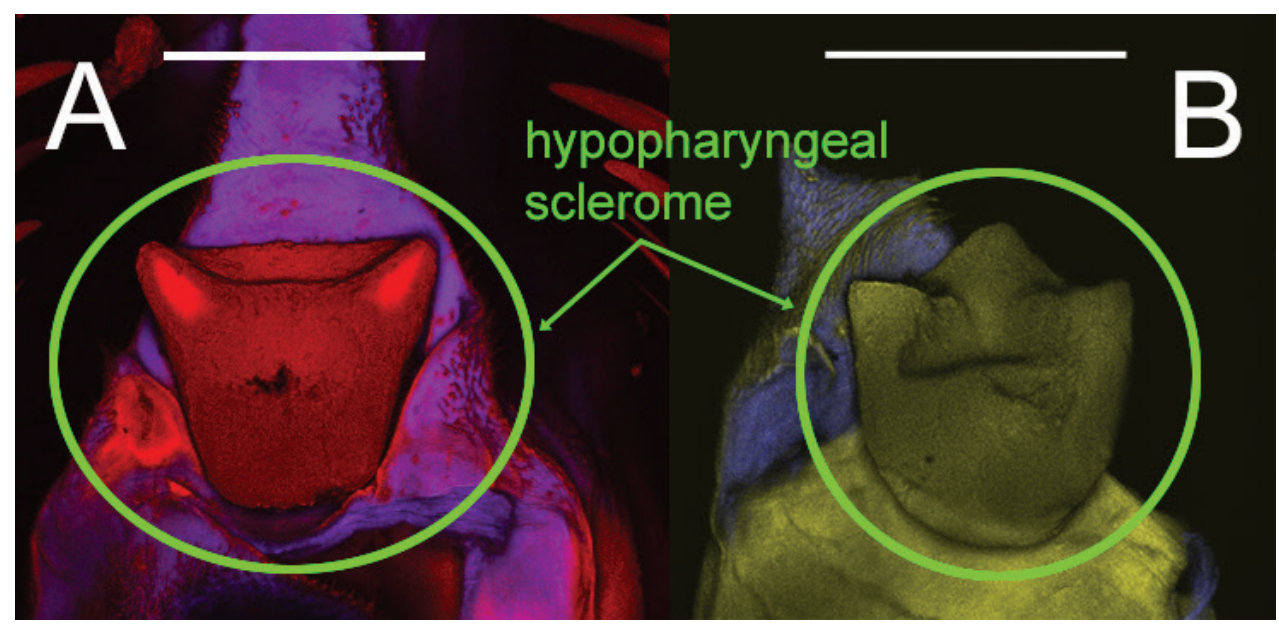

Figure 12. Hypopharyngeal scleromes of two Eleodes species: A E. (Melaneleodes) carbonarius B E. (Litheleodes) extricatus. Scale bars $=200 \mu \mathrm{m}$.

colorous brown. Meso- and metathoracic tergites wider than long, each with a heavily sclerotized transverse line present on anterior fifth. Thoracic tergites sparsely setose on dorsal surfaces, lateral margins more densely setose. Mesothoracic spiracle simple, ovate, approximately $1.5 \times$ size of abdominal spiracles; reduced metathoracic spiracle visible, less than one-fourth size of mesothoracic spiracle. Legs. Prothoracic leg slightly longer, much thicker than meso- and metathoracic legs; prothoracic tarsungulus strongly sclerotized, sickle-shaped; prothoracic trochanter with two stout ventromedially spines; prothoracic femur with ventromedial row of two spines and three to five longer setae, dorsal surface with faintly indicated basal sclerotized band; prothoracic tibia with ventromedial row of five to six spines or spinose setae, dorsal surface slightly more sclerotized than ventral surface. Mesotibia with four to five ventromedial spines.

Abdomen. Abdominal tergites and sternites I-VIII light tan, with slightly darker transverse striated bands present along posterior margins8, forming near contiguous unicolorous band around segments. Abdominal sternite I moderately clothed in long erect setae to posterior pigmented band. Abdominal laterotergites with lateral margins distinctly pigmented. Abdominal segment IX (pygidium) triangular in dorsal view, gradually reflexed to apex, urogomphi absent, apex lacking a distinct tooth, moderately clothed in short and mid length erect setae, dorsally sclerotization uniform throughout, lacking maculations; marginal row of 18-20 socketed spines present, arranged as single row around posterior two-thirds to one half of segment. Abdominal sternites 1-8 lacking longitudinal tomentose bands along lateral margins. Pygopods short, subconical, each with 17-24 erect setae.

Diagnosis. Eleodes subnitens larvae can be separated from the other currently known Eleodes species by the pentagonal hypopharyngeal sclerome, prothoracic tergum wider than long, 8th and 9th abdominal tergites not darker than proceeding segments, lack of a caudal tooth on the pygidium, and the presence of 5-6 ventromedial spines on the protibia. 


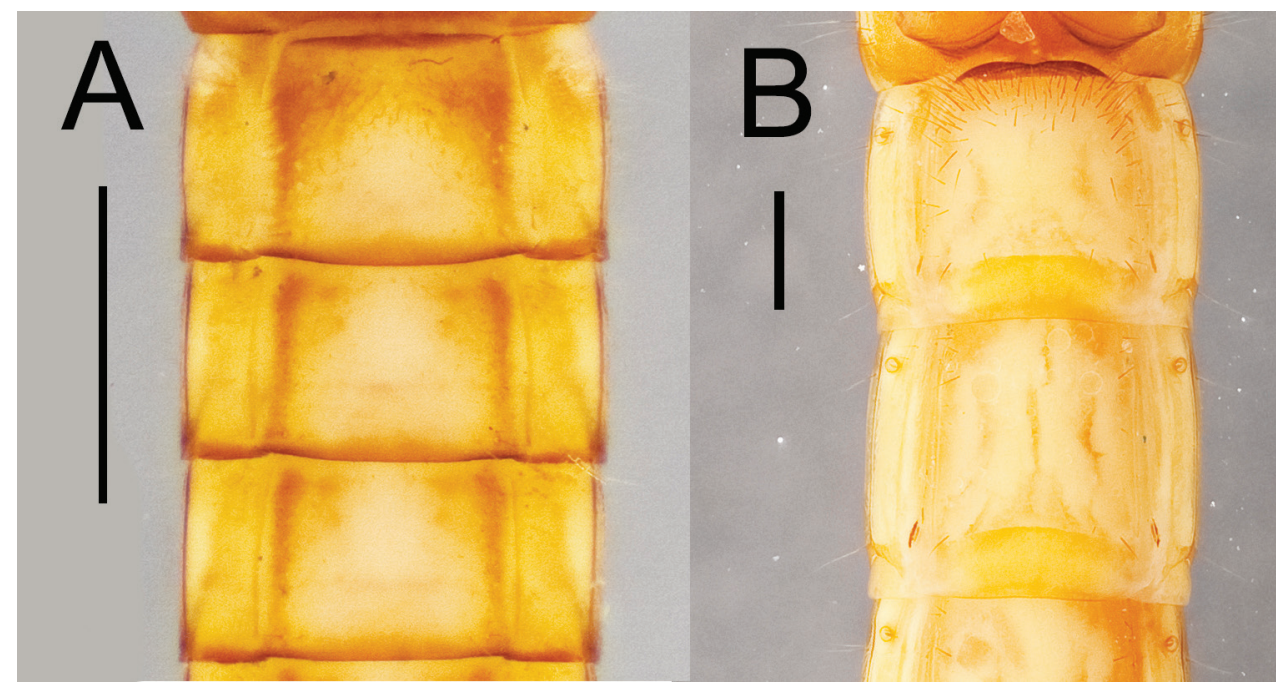

Figure I3. Abdominal sternites I and II for two Eleodes species: A E. (Eleodes) caudiferus B E. (Litheleodes) extricatus. Scale bars $=1 \mathrm{~mm}$.

\section{Subgenus Tricheleodes Blaisdell, 1909}

\section{Eleodes (Tricheleodes) pilosus Horn, 1870}

http://species-id.net/wiki/Eleodes_pilosus

Figures 3D, 6C, 10D, 14B

Material examined. Larval E. pilosus specimens were reared from adults with the following collecting information: "NEVADA: Washoe Co. / N39¹6.427', W11947.070' / November 14, 2011 / P.Skelley, sifting lakeside dunes". A total of 208 eggs and larvae were reared and examined for this study, of which 94 survived until the 2 nd instar or later. The following description is based on a detailed examination of nine 8-11th instar specimens.

Description. TL: 14.2-26.0 mm, PW: 1.7-3.3 mm, PL: 1.4-3.4mm, HW: 1.6$2.6 \mathrm{~mm}$.

Head. Prognathous, weakly flattened, narrower than prothorax; sides rounded, strongly constricted before occipital foramen; color nearly as in body segments. Epicranial stem short, one-fourth head capsule length; frontal arms U-shaped, partially obscured by sculpturing. Frons and dorsal portion of epicranial plates rugose; sparsely setose; densely punctate, punctures minute, lacking setae. Ventrolateral portions of epicranial plates densely setose; setae golden, erect, most longer than antennal segment 2 , interspersed with shorter setae; two stemmata present on each plate, pigmented spots often faded. Clypeus trapezoidal; swollen, weakly transversely raised medially; moderately punctate, rugose in basal half. Labrum slightly swollen, basal fourth darkly pigmented; sides rounded, minutely tomentose; two transverse rows of six to eight erect setae present medially and subapically; anterior margin straight. Epipharynx (Fig. 10D) anterior setal row with six stout spiniform setae, anterolateral margins with micro-setation; seven 


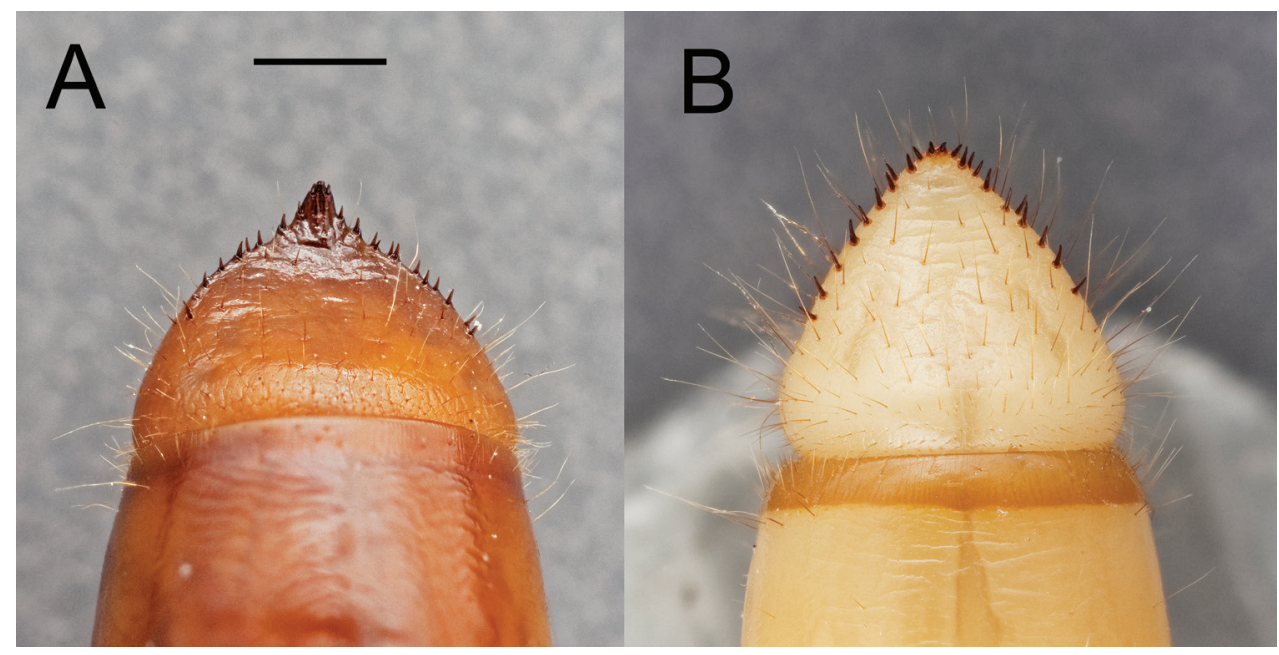

Figure 14. Pygidia of two Eleodes species: A E. (Eleodes) hispilabris B E. (Tricheleodes) pilosus. Scale bar $=1 \mathrm{~mm}$.

anterior sensory papillae present, arranged in two irregular longitudinal rows; four subanterior sensory papillae present, arranged as a transverse row subtended by two spinose setae; seven posterior sensory papillae present, arranged in an irregular cluster. Tormae asymmetrical, left side torma smaller with or without a small spine near emergent edge. Hypopharyngeal sclerome pentagonal, tricuspidate. Gula distinct, trapezoidal, widest in basal half. Antenna three segmented, cylindrical; first segment longer than second.

Thorax. Light to dark tan, darker longitudinally striated bands present on anterior margin of prothoracic tergum and posterior 5 th of all thoracic tergites. Sparsely setose along dorsal margins of terga near striated bands, lateral margins more densely setose. Prothoracic tergum subquadrate, $1.5 \times$ length of meso- or metaterga; lateral margins with pigmented band along entire length. Mesothoracic spiracle simple, ovate, approximately $1.5 \times$ size of abdominal spiracle; reduced metathoracic spiracle visible, less than onefourth size of mesothoracic spiracle. Prothoracic leg slightly longer, much thicker than meso- and metathoracic legs; tarsungulus strongly sclerotized, sickle-shaped; trochanter with two stout spines ventromedially, tibia and tarsus each with a ventromedial row of four to seven spines, number of spines often differing between prolegs. Dorsal surface of protibia (at rest) with basal sclerotized band; dorsal surface of protarsus sclerotized.

Abdomen. Light to dark tan, darker longitudinally striated bands present on posterior 5 th of segments I-VIII. Abdominal sternite I moderately clothed in long erect setae, sparser medially, extending to posterior pigmented band, abdominal tergite I and segments II-VIII sparsely clothed in short to mid length setae. Lateral margins of abdominal laterotergites I-VIII darkly pigmented, ventral margin with two pigmented bands. Abdominal segment IX (pygidium) triangular in dorsal view, moderately clothed in long erect setae; marginal row of 10-20 socketed spines present apical half, apex not forming distinct sclerotized projection. Pygopods short, subconical, each with 16-20 erect spines. 
Diagnosis. Eleodes pilosus larvae can be separated from the other currently known Eleodes species by the pentagonal hypopharyngeal sclerome, lack of a caudal tooth on the pygidium, presence of 8-14 marginal spines on the pygidium, subquadrate prothoracic tergum, and having abdominal sternite I moderately clothed in long erect setae to posterior pigmented band.

\section{Key to the late instar larvae of 13 Eleodes species}

1 Lateral margins of abdominal sternites I-IX pigmented, with golden tomentose setae (Fig. 13A). Eleodes caudiferus LeConte

1' Lateral margins of abdominal sternites I-IX unpigmented, lacking tomentose

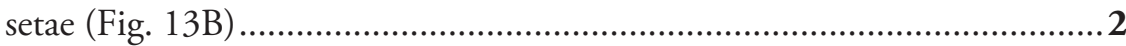

2 (1') Apex of pygidium attenuated and sclerotized, forming a distinct projection (Fig. 14A)

2' Apex of pygidium somewhat attenuated, lightly or unsclerotized, not forming distinct projection (Fig. 14B) ............................................................ 5

3 (2) Anterolateral margins of epipharynx with micro-setation (Fig.8, 9A-B,D, $10 \mathrm{~A}-\mathrm{D})$, lacking stout setae. Eleodes armatus LeConte

3' Anterolateral margins of epipharynx with stout setae (Fig. 9C) ...................4

4 (3) Mesotarsus with row of three ventromedial spines; ventral portion epicranial plates with row of six or more long setae along anterior margin near buccal cavity, confluent with setae on lateral portions of plates; prothoracic femur with ventromedial row of 13-14 spines Eleodes tenuipes Casey

4' Mesotarsus with two ventromedial spines, ventral portion epicranial plates with row of four to five long setae along anterior margin, not confluent with setae on lateral portions of plates; prothoracic femur with ventromedial row of $6-10$ spines Eleodes hispilabris (Say)

5 (2') Granulated band along lateral margins of protergum faint, concolorous with protergal disc (Fig. 7A)

5) Granulated band along lateral margins of protergum distinct, darker than protergal disc (Fig. 7B-C) ................................................................ 8

6 (5) Hypopharyngeal sclerome pentagonal, tricuspidate (Fig.12B); ligula apex lacking microsetae, two long subapical setae present ventrally, eight or more subapical setae present dorsally (Fig.11B); pigmented band present along posterior margin of abdominal sterna, integument usually tan

\section{Eleodes wheeleri Aalbu, Smith, \& Triplehorn}

6) Hypopharyngeal sclerome trapezoidal (Fig.12A); ligula apex glabrous, four long subapical setae present, two ventrally and two dorsally (Fig.11A); pigmented band absent along posterior margin of abdominal sterna, integument usually dark brown

7 (6) Terga dark brown, nearly black, throughout; prothoracic tergum wider than long, $1.2 \times$ or more length of meso- or metaterga; posterior pigmented band 
on abdominal terga I-VIII darker than rest of segment; abdominal sternites nearly concolorous with tergites......................... Eleodes carbonarius (Say)

7' Terga medium brown, lighter towards margins; prothoracic tergum subquadrate, $1.5 \times$ length of meso- or metaterga; posterior pigmented band on abdominal terga I-VIII concolorous with rest of segment; abdominal sternites lighter than tergites Eleodes anthracinus (Blaisdell)

8 (5') Pigmented band around posterior margin of abdominal segments dark along anterior edge, fading to segment color posteriorly (Fig. 4A).

Eleodes nigropilosus (LeConte)

8' Pigmented band around posterior margin of abdominal segments unicolorous, darker than rest of segment throughout.

9 (8') Abdominal sternite I moderately clothed in long erect setae to posterior pigmented band; seven anterior sensory papillae present on epipharnyx in all specimens examined. Eleodes pilosus (Horn)

9' Abdominal sternite I with sparsely setose on at most anterior half; six anterior sensory papillae present on epipharnyx in all specimens examined ............10

10 (9') Antennal segment I longer than antennal segment II (Fig. 7A-B); gula length less than maximum width Eleodes extricatus (Say)

10' Antennal segment I subequal to antennal segment II (Fig. 7C); gula length subequal or greater than maximum width. .11

11 (10') Pygidium with marginal row of 8-14 socketed spines; prothoracic tergum subquadrate, $1.5 \times$ length of meso- or metaterga.... Eleodes tribulus Thomas

11' Pygidium with marginal row of 18-20 socketed spines; prothoracic tergum wider than long, $1.2 \times$ or more length of meso- or metaterga.....................12

12 (11') Eighth and ninth abdominal tergites more darkly pigmented than preceding segments, protibia with ventromedial row of 3-4 spines ...Eleodes goryi Solier 12' Eighth and ninth abdominal tergites with same pigmentation as preceding segments; protibia with ventromedial row of 5-6 spines

Eleodes subnitens LeConte

\section{Notes on additional species}

Eleodes spinipes (Solier). One specimen of Eleodes spinipes ventricosus (TB08942) was reared to a late instar, 9th or 10th, in the lab. However, the specimen apparently died in its rearing container while molting and suffered some damage, thus obscuring many characters. What could be seen of the epipharnyx, ligula, and abdominal segment IX, including the presence of an apical tooth on the pygidium, place it with Eleodes armatus, E. hispilabris, and E. tenuipes in the subgenus Eleodes. The presence of spinose setae along the anterolateral margins of the epipharnyx placed it closest to E. hispilabris, and E. tenuipes. 


\section{Previously described species}

Eleodes dentipes Eschscholtz. Little comparative data to separate the species can be drawn from Gissler (1878). Blaisdell (1909) provides a more detailed description, but likewise does not include many characters currently necessary to differentiate the species.

Eleodes giganteus Mannerheim. Little comparative data to separate this species from the other currently described Eleodes larvae can be drawn from Gissler (1878).

Eleodes pimelioides (Mannerheim). Little comparative data to separate this species from the other currently described Eleodes larvae can be drawn from Hyslop (1912).

Eleodes suturalis (Say). The thorough description in Wade and St. George (1923) easily places this species within the subgenus Eleodes based on the epipharnyx and the apical tooth on the pygidium. It also appears to have spinose setae on the anterolateral margins of the epipharnyx, as in E. hispilabris, E. spinipes, and E. tenuipes.

Eleodes tricostatus (Say). McColloch (1918) describes the larvae as black in color after the first instar. The larvae of E. carbonarius and E. anthracinus, the only other Melaneleodes larvae known, are similarly dark. The picture provided by McColloch (plate 5, image B), also looks similar to E. carbonarius in gestalt.

Eleodes vandykei Blaisdell. Little comparative data to separate this species from the other currently described Eleodes larvae can be drawn from Hyslop (1912).

\section{Discussion}

As adult morphology in many Eleodes species may be heavily influenced by participation in mimicry rings with co-occurring species (Doyen and Somerby 1974), the addition of characters from larval morphology may help produce a more accurate phylogeny based on morphological data than one using adult morphology alone. The presented phylogeny (Fig. 1) demonstrates the utility of larval morphology in resolving at least some relationships within the genus Eleodes. The subgenus Melaneleodes was well supported based on several synapomorphies present in the two included species. The subgenus Eleodes showed two synapomorphies supporting a relationship for three of the included species, but did not recover a clade containing all of the current or presumed species from the nominate subgenus. Both E. tribulus and E. caudiferus are somewhat unusual members of the subgenus based on adult morphology as well; hence further research is needed to accurately place them within the subgeneric classification. The inclusion of more taxa should increase phylogenetic accuracy and help illuminate the currently unresolved relationships between the Eleodes subgenera (Heath et al. 2008). It is likely that extensive modifications to the matrix and key will be needed as more larvae become known. It is also possible that some species, particularly closely related ones, cannot be separated based on larval characters alone.

By producing matrix-based descriptions within $\mathrm{mx}$, we are creating a growing repository of digital morphological and specimen data, already available through the tenebrio- 
nidbase.org portal, including an online multi-entry key (http:/tenebrionidbase.org/public/ clave) to the currently known Eleodes larvae. Characters and states from the matrix and key will also be linked to the developing Coleoptera Anatomy Ontology project (ColAO).

\section{Acknowledgements}

We would like to thank the following people for collecting or helping to rear specimens for this project: Paul Skelley, Stephanie Delgado, Soon Flynn, Amanda Smith, Jazmine Mayberry, Tiffany Gruna, Erik Posch, and Wade Wilber. James Thostenson and Andrew Johnston provided technical and operational assistance with the CLSM at the American Museum of Natural History. Rolf Aalbu, Nico Franz, and David Grimaldi provided insightful comments and suggestions to improve the manuscript. Funding was provided by the International Institute for Species Exploration at Arizona State University and the NSF ARTS program (DEB-1258154).

\section{References}

Aalbu RA, Smith AD, Triplehorn CA (2012) A revision of the Eleodes subgenus Caverneleodes with new species and notes on cave breeding Eleodes (Tenebrionidae: Amphidorini). Annales Zoologici 62: 199-216. doi: 10.3161/000345412X652729

Allsopp PG (1980) The biology of false wireworms and their adults (soil-inhabiting Tenebrionidae) (Coleoptera): a review. Bulletin of Entomological Research 70: 343-379. doi: $10.1017 / S 0007485300007628$

Blaisdell FE (1909) A monographic revision of the Coleoptera belonging to the Tenebrionid tribe Eleodiini inhabiting the United States, lower California, and adjacent islands. Bulletin of the United States National Museum 63: 1-524. doi: 10.5479/si.03629236.63.1

Brown KW (1973) Description of immature stages of Philolithus densicollis and Stenomorpha puncticollis with notes on their biology (Coleoptera, Tenebrionidae, Tentyriinae). Postilla 162: 1-28.

Calkins CO, Kirk VM (1975) False wireworms of economic importance in South Dakota (Coleoptera: Tenebrionidae). South Dakota Agricultural Experiment Station Bulletin: 115-120.

Doyen JT (1988) Descriptions of some phylogenetically important larvae of Tenebrionidae (Coleoptera). Coleopterists Bulletin 42: 285-301.

Doyen JT, Somerby RE (1974) Phenetic similarity and Mullerian mimicry among darkling ground beetles (Coleoptera:Tenebrionidae). Canadian Entomologist 106: 759-772. doi: 10.4039/Ent106759-7

Gissler CF (1878) On coleopterous larvae of the family of Tenebrionidae. Bulletin of the Brooklyn Entomological Society 1: 18-19.

Goloboff PA (1999) NONA (NO NAME), version 2.0 (for Windows). Published by the author, Tucumán, Argentina.

Goloboff P, Farris J, Nixon K (2008) TNT: a free program for phylogenetic analysis. Cladistics 24: 774-786. doi: 10.1111/j.1096-0031.2008.00217.x 
Heath TA, Hedtke SM, Hillis DM (2008) Taxon sampling and the accuracy of phylogenetic analyses. Journal of Systematics and Evolution 46: 239-257.

Hyslop JA (1912) The false fireworms of the Pacific Northwest. United States Bureau of Entomology Report 95: 73-87.

Lawrence JF (1991) Order Coleoptera. In: Stehr FW (Ed) Immature Insects, Vol. 2. Kendall/ Hunt Publishing Co., Dubuque, Iowa, 144-298.

McColloch JW (1918) Notes on false fireworms with especial reference to Eleodes tricostata. Journal of Economic Entomology 11: 212-224.

Mullins PL, Kawada R, Balhoff JP, Deans AR (2012) A revision of Evaniscus (Hymenoptera, Evaniidae) using ontology-based semantic phenotype annotation. ZooKeys 223: 1-38. doi: $10.3897 /$ zookeys.223.3572

Nixon KC (2002) WinClada ver. 1.00.08. Published by the author, Ithaca, NY.

Say T (1823-1824) Descriptions of coleopterous insects collected in the late expedition to the Rocky Mountains performed by order of Mr. Calhoun, Secretary of War, under the command of Major Long. Journal of the Academy of Natural Sciences of Philadelphia 3: 139-216 [1823]; 238-282, 298-331, 403-462 [1824].

St. George RA (1924) Studies of the Larvae of North American Beetles of the Subfamily Tenebrioninae with a description of the larva and pupa of Merinus laevis (Olivier). Proceedings of the Unites States National Museum 65: 1-22. doi: 10.5479/si.00963801.65-2514.1

Talamas EJ, Masner L, Johnson NF (2011) Revision of the Malagasy genus Trichoteleia Kieffer (Hymenoptera, Platygastroidea, Platygastridae). ZooKeys 80: 1-126. doi: 10.3897/ zookeys. 80.907

Thomas DB (1984) The life history and ecology of the pinacate beetle, Eleodes armatus LeConte (Tenebrionidae). Coleopterists Bulletin 38: 150-159.

Triplehorn CA, Aalbu RL (1987) Eleodes blaisdelli Doyen, a synonym of E. caudatus (Horn) (Coleoptera: Tenebrionidae). Coleopterists' Bulletin 41: 370-372.

Triplehorn CA, Thomas DB (2011) Studies in the genus Eleodes Eschscholtz with a revision of the subgenus Melaneleodes Blaisdell and Omegeleodes, new subgenus (Coleoptera: Tenebrionidae: Eleodini). Transactions of the American Entomological Society 137: 251-281.

Wade JA, St. George RA (1923) Biology of the false wireworm, Eleodes suturalis. Journal of Agricultural Research 36: 547-566.

Winterton SL (2009) Revision of the stiletto fly genus Neodialineura Mann (Diptera: Therevidae): an empirical example of cybertaxonomy. Zootaxa 2157: 1-33.

Yoder MJ, Valerio AA, Polaszek A, Masner L, Johnson N (2009) Revision of Scelio pulchripennis - group species (Hymenoptera, Platygastroidea, Platygastridae). In: Johnson N (Ed) Advances in the systematics of Hymenoptera. Festschrift in honour of Lubomír Masner. ZooKeys 20: 53-118. doi: 10.3897/zookeys.20.205

Yoder MJ, Mikó I, Seltmann KC, Bertone MA, Deans AR (2010) A Gross Anatomy Ontology for Hymenoptera. PLoS ONE 5(12): e15991. doi: 10.1371/journal.pone.0015991 


\section{Appendix I}

1. Head - orientation: (0) prognathous or weakly declined; (1) hypognathous

2. Head - shape: (0) rounded; (1) weakly dorsoventrally flattened; (2) strongly dorsoventrally flattened

3. Head - width: (0) narrower than prothorax; (1) nearly equal to prothorax; (2) wider than prothorax

4. Head - sides: (0) rounded; (1) angular

5. Head - constriction: (0) strongly constricted before occipital foramen; (1) weakly constricted before occipital foramen

6. Head - color: (0) medium brown; (1) brown-grey; (2) ferruginous; (3) dark brown; (4) light tan; (5) dark tan

7. Head - color vs body color: (0) same or nearly the same as body segments; (1) more heavily pigmented than body segments

8. Head - punctation: (0) impunctate; (1) minute; (2) moderate

9. Head - punctation density: (0) impunctate; (1) sparse, separated by more than 4 puncture diameters; (2) moderate, separated by 2-4 puncture diameters; (3) dense, separated by 1-2 puncture diameters; (4) nearly confluent, separated by less than a puncture diameter; (5) confluent, at least some punctures merged

10. Epicranial suture - stem length: (0) approximately one-third head capsule length; (1) approximately one-fourth head capsule length

11. Epicranial suture - frontal arms: (0) U-shaped, not obscured by sculpturing; (1) U-shaped, partially obscured by sculpturing; (2) V-shaped, not obscured by sculpturing; (3) V-shaped, obscured by sculpturing

12. Frons - sculpturing: (0) smooth; (1) faintly rugose; (2) rugose

13. Epicranial plates - dorsal sculpturing: (0) smooth; (1) faintly rugose; (2) rugose

14. Frons - non-primary setae: (0) absent; (1) present

15. Lateral portions of epicranial plates: (0) sparsely setose; (1) moderately setose; (2) densely setose

16. Ventral portions of epicranial plates - setation 1: (0) with row of four to five long setae along anterior margin near buccal cavity, not confluent with setae on lateral portions of plates; (1) with row of six or more long setae along anterior margin near buccal cavity confluent with setae on lateral portions of plates; (2) with two long setae along anterior margin near buccal cavity, not confluent with setae on lateral portions of plates

17. Ventral portions of epicranial plates - setation 2: (0) patch of short setae medially forming a triangular pattern with its base near the anterior margin

18. Stemmata: (0) two present on each epicranial plate, pigmented spots often faded

19. Clypeus - shape: (0) trapezoidal

20. Clypeus - inflation: (0) not swollen; (1) swollen

21. Clypeus - punctation density: (0) impunctate; (1) sparse, separated by more than 4 puncture diameters; (2) moderate, separated by $2-4$ puncture diameters; 
(3) dense, separated by 1-2 puncture diameters; (4) nearly confluent, separated by less than a puncture diameter; (5) confluent, at least some punctures merged

22. Clypeus - pigmentation: (0) unicolorous; (1) darker medially in basal half; (2) basal half darker; (3) apical half darker

23. Labrum - inflation: (0) not swollen; (1) swollen

24. Labrum - pigmentation: (0) unicolorous; (1) basal half more darkly pigmented

25. Labrum - sides: (0) rounded; (1) straight

26. Labrum - medial setal row: (0) absent; (1) six to seven erect setae; (2) seven to eight erect setae; (4) ten to fourteen erect setae; (5) four erect setae; (6) two erect setae

27. Labrum - subapical setal row: (0) absent; (1) six to seven erect setae; (2) seven to eight erect setae; (4) ten to fourteen erect setae

28. Labrum - anterior margin: (0) straight to weakly emarginate; (1) medially emarginate

29. Epipharynx - anterior setal row: (0) absent; (1) with six stout spiniform setae; (2) with eight or more stout spiniform setae

30. Epipharynx - anterolateral margins: (0) with stout spinose setae; (1) with microsetation; (2) lacking setation

31. Epipharnyx - anterior sensory papillae (spinule) number: (0) six; (1) seven; (2) eight; (3) four; (4) five

32. Epipharnyx - anterior sensory papillae (spinule) arrangement: (0) two irregular diagonal rows; (1) two irregular longitudinal rows; (2) two irregular rows, each with two posterior papillae and one near the anterior margin; (3) irregular cluster

33. Epipharnyx - subanterior sensory papillae: (0) transverse row of four small sensory papillae subtended by two spinose setae

34. Epipharnyx - posterior sensory papillae number: (0) six; (1) seven; (2) eight

35. Epipharnyx - posterior sensory papillae arrangement: (0) two irregular rows; (1) irregular cluster

36. Tormae: (0) strongly asymmetric; (1) weakly asymmetric

37. Tormae 2: (0) symmetrical; (1) asymmetrical, left torma smaller; (2) asymmetrical, left torma larger; (3) asymmetrical, left torma smaller, with or without small spine near emergent edge

38. Ligula - setae: (0) apex glabrous, four long subapical setae present, two ventrally and two dorsally; (1) apex densely microsetose, two long subapical setae present ventrally; (2) apex lacking microsetae, two long subapical setae present ventrally, eight or more subapical setae present dorsally; (3) apex with fringe of 6-10 long setae, medially with longitidinal row of short stout setae; (4) apex with median longitudinal row of microsetae dorsally, two long subapical setae present ventrally

39. Hypopharyngeal sclerome: (0) trapezoidal; (1) pentagonal, tricuspidate; Shape of hypopharyngeal sclerome

40. Gula: (0) distinct, hexagonal, widest near middle; (1) distinct, weakly trapezoidal, nearly rectangular; (2) trapezoidal, widest at base

41. Gula - fusion: (0) sutures visible throughout; (1) sutures fused, not visible in basal half

42. Gula - length: (0) less than maximum width; (1) subequal or greater than maximum width 
43. Antenna: (0) three segmented, cylindrical, first segment longer than second; (1) three segmented, cylindrical, first segment subequal to second; (2) three segmented, cylindrical, first segment shorter than second

44. Antenna - segment 2 sensorium: (0) forming a single incomplete ring around the base of segment 3 ; (1) consisting of many small rounded sensoria around base of segment 3

45. Thoracic tergites - color: (0) grey-brown; (1) medium brown; (2) ferruginous; (3) dark brown; (4) light tan

46. Prothoracic sternite - color anterior to legs: (0) grey-brown; (1) medium brown; (2) ferruginous; (3) dark brown; (4) light brown

47. Thoracic sternite color - posterior to prolegs: (0) tan; (1) light brown; (2) medium brown

48. Prothoracic tergum - anterior transverse striated band: (0) absent; (1) present along anterior fourth, lighter than tergal disc; (2) present along anterior fourth, darker than tergal disc

49. Thoracic tergites - posterior transverse band: (0) absent; (1) present along posterior 5th of all thoracic tergites, striated; (2) present along posterior 6th of all thoracic tergites; striated (3) present along posterior 4th of all thoracic tergites, striated; (4) present, not striated

50. Thoracic tergites - posterior striated band color: (0) absent; (1) forming a gradient from darker brown anteriorly to lighter brown along posterior border; (2) unicolorous, brown, darker midtergite

51. Mesothoracic tergite - sclerotized transverse line: (0) absent; (1) present on anterior fifth, heavily sclerotized; (2) present on anterior fifth, faint

52. Metathoracic tergite - sclerotized transverse line: (0) absent; (1) present on anterior fifth, heavily sclerotized; (2) present on anterior fifth, faint

53. Thoracic tergites - setae: (0) absent; (1) eight evenly arranged setae present on dorsal surface of each thoracic tergite, lateral margins more densely setose; (2) more than eight dorsal setae present, pattern variable; (3) dense transverse band of short setae near anterior margins of meso- and metatergites

54. Prothoracic tergum - shape: (0) subquadrate, $1.5 \times$ or more length of meso- or metaterga; (1) wider than long, $1.2 \times$ or more length of meso- or metaterga

55. Prothoracic tergum - lateral margins: (0) granulated band faint, concolorous with protergal disc; (1) granulated band distinct, darker than protergal disc; (2) granulated band absent

56. Meso- and metaterga - shape: (0) wider than long

57. Meso- and metaterga - lateral margin: (0) lacking pigmented bands; (1) pigmented bands present

58. Mesothoracic spiracle: (0) simple, ovate, approximately $1.5 \times$ size of abdominal spiracles

59. Prothoracic legs: (0) slightly longer and much thicker than meso- and metathoracic legs; (1) slightly longer and slightly thicker than meso- and metathoracic legs

60. Prothoracic legs - tarsungulus: (0) strongly sclerotized and sickle-shaped; (1) strongly sclerotized, attenuated and slightly hooked 
61. Prothoracic legs - trochanter: (0) with row of two stout spines and two longer setae ventro-medially; (1) with row of two stout spines ventro-medially; (2) one stout ventro-medial spine present

62. Prothoracic legs - femur: (0) with ventro-medial row of two spines and three to five longer setae; (1) with ventro-medial row of three to four spines and four to five longer setae; (2) with ventro-medial row of five to six spines; (3) with ventro-medial row of six to ten spines; (4) with ventro-medial row of 13 to 14 spines; (5) with ventro-medial row of three spines; (6) with ventro-medial row of four spines

63. Prothoracic legs - tibia: (0) with ventro-medial row of three to four spines; (1) with ventro-medial row of five to six spines; (2) with ventro-medial row of eight to eleven spinose setae; (3) with eight or more spines ventro-medially, not forming a regular row

64. Prothoracic legs - femur dorsal surface (at rest): (0) with faintly indicated basal sclerotized band; (1) lacking basal sclerotized band

65. Prothoracic legs - tibia dorsal surface (at rest): (0) slightly more sclerotized than ventral surface

66. Mesotibia - posterior surface: (0) row of three spines; (1) row of two spines; (2) row of four to five spines; (3) row of five to seven spinose setae; (4) four spines in $2 \times 2$ pattern

67. Abdominal tergites 1-7 - color: (0) light tan; (1) grey-brown; (2) medium brown; (3) ferruginous; (4) dark brown

68. Abdominal tergites 1-7 - color gradation: (0) unicolorous; (1) lightening towards lateral margins; (2) darkening towards lateral margins

69. Abdominal sternites - color: (0) light tan; (1) dark tan; (2) ferruginous

70. Abdominal tergites 1-8 - transverse striated bands: (0) absent; (1) barely visible on posterior 5 th of segments; (2) distinct on posterior 5th of segments

71. Abdominal sternites 1-8 - transverse striated bands: (0) absent; (1) barely visible on posterior 5 th of segments; (2) distinctly visible, forming near contiguous band with tergal band

72. Abdominal sternite I - setae: (0) absent; (1) sparsely clothed in long erect setae from anterior margin to near midline; (2) moderately clothed in long erect setae to posterior pigmented band; (3) moderately clothed in long erect setae from anterior margin to near midline; (4) tomentose in anterior third, denser along near lateral margins; (5) sparsely clothed in long erect setae along anterior margin

73. Abdominal segments 2-8 - setae: (0) absent; (1) each segment with two sparse transverse bands of long erect setae; (2) each segment with two sparse transverse bands of long erect setae, posterior margin of segment 8 denser setal band; (3) otherwise

74. Abdominal tergites 1-8 - posterior margin color gradation: (0) dark along anterior edge, fading to segment color posteriorly; (1) unicolorous, darker than rest of segment throughout

75. Abdominal tergite 8 - pigmentation: (0) more darkly pigmented than preceding segments; (1) same pigmentation as preceding segments 
76. Abdominal tergite 9 - pigmentation: (0) more darkly pigmented than preceding segments; (1) same pigmentation as preceding segments; (2) lighter than preceding segments

77. Abdominal laterotergites: (0) concolorous with tergites, lacking distinct pigmented margins; (1) lateral margins distinctly pigmented

78. Abdominal segment IX, pygidium - dorsal aspect: (0) triangular in dorsal view, gradually reflexed to apex, apex not forming a distinct tooth; (1) triangular in dorsal view, gradually reflexed to apex, apex attenuated and sclerotized, forming a distinct tooth; (2) triangular in dorsal view, gradually reflexed to apex, apex attenuated and sclerotized, rarely forming a small tooth in some specimens; (3) triangular in dorsal view, gradually reflexed to apex, apex with distinct urigomphi

79. Abdominal segment IX, pygidium - setae: (0) absent; (1) sparsely clothed in short and mid length erect setae; (2) moderately clothed in short and mid length erect setae; (3) few primary setae

80. Abdominal segment IX, pygidium - dorsal sculpturing: (0) dorsally more sclerotized in apical two-thirds with faint maculations; (1) sclerotization uniform throughout, lacking maculations

81. Abdominal segment IX, pygidium - marginal row of socketed spines: (0) 14-18 spines; (1) 18-20 spines; (2) 17-23 spines; (3) 22-24 spines; (4) 8-14 spines; (5) 27 spines; (6) 28-38 spines; (7) four spines

82. Abdominal segment IX, pygidium - marginal row of socketed spines 2: (0) forming a single row around posterior two-thirds to one half of segment; (1) forming two or three irregular rows around posterior two-thirds to one half of segment, narrowing to single row around apex; (2) four distinct, regular spines

83. Abdominal sternites I-VIII, longitudinal tomentose bands along lateral margins: (0) present; (1) absent

84. Abdominal segment $X$ - pygopods: (0) short, subconical; (1) longer, tip inverted

85. Abdominal segment $X$ - pygopod setation: (0) each with 9-12 erect setae; (1) each with 11-15 erect setae; (2) each with 17-24 erect setae; (3) each with 10 or more erect setae onmore heavily sclerotized posterior face

86. Urogomphi: (0) absent; (1) present, connected at base or complex; (2) present, paired 


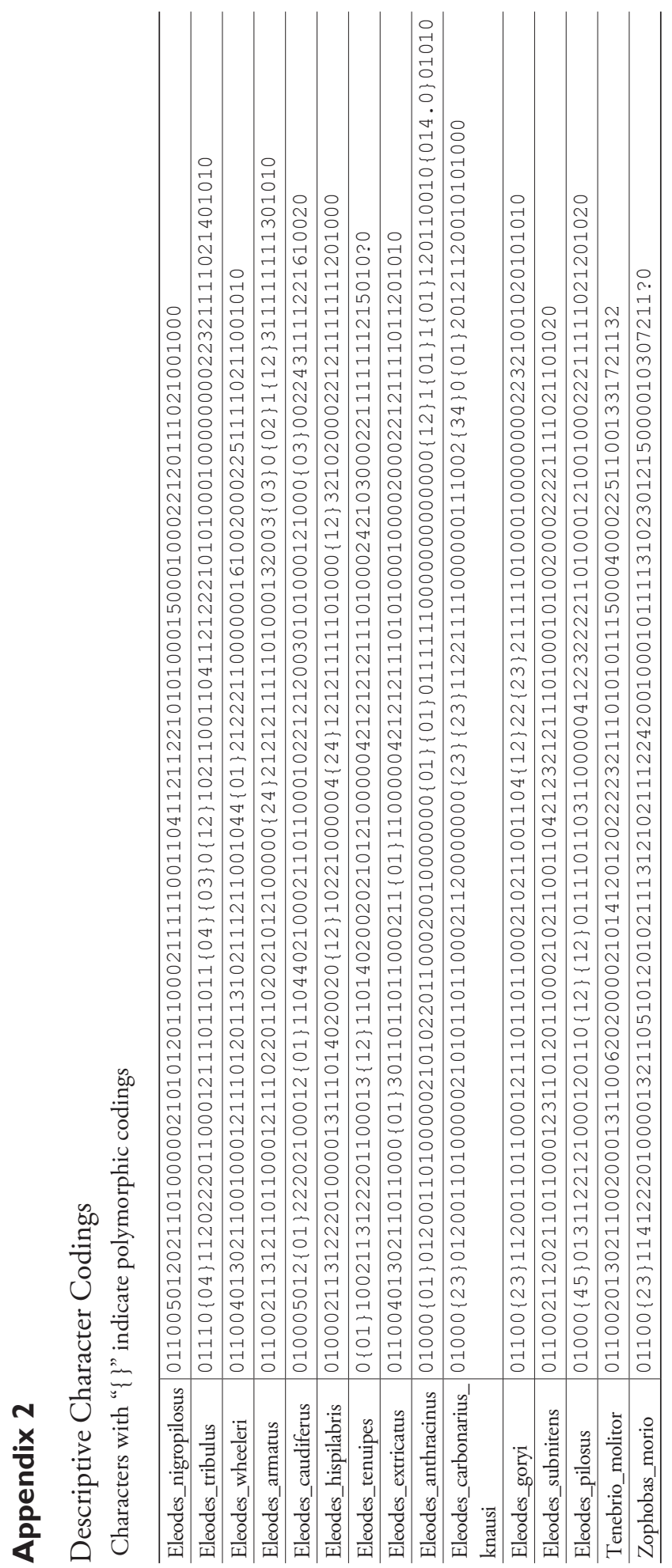




\section{Appendix 3}

\section{Cladistic Morphological Character Matrix}

1. Head - width: (0) nearly equal to prothorax; (1) narrower than prothorax

2. Head - color vs body color: (0) more heavily pigmented than body segments; (1) same or nearly the same as body segments

3. Head - punctation density: (0) impunctate-nearly confluent, separated by less than a puncture diameter; (1) sparse, separated by more than 4 puncture diameters; (2) moderate, separated by 2-4 puncture diameters; (3) dense, separated by $1-2$ puncture diameters

4. Epicranial suture - stem length: (0) approximately one third head capsule length; (1) approximately one fourth head capsule length

5. Epicranial suture - frontal arms: (0) sinuate; (1) U shaped

6. Frons - sculpturing: (0) distinctly rugose; (1) faintly rugose

7. Epicranial plates - dorsal sculpturing: (0) distinctly rugose; (1) faintly rugose

8. Lateral portions of epicranial plates: (0) sparse to moderately setose; (1) densely setose

9. Ventral portions of epicranial plates - setation: (0) with row of four to five long setae along anterior margin near buccal cavity, not confluent with setae on lateral portions of plates; (1) with row of six or more long setae along anterior margin near buccal cavity, confluent with setae on lateral portions of plates; (2) with two long setae along anterior margin near buccal cavity, not confluent with setae on lateral portions of plates

10. Clypeus - shape: (0) swollen; (1) not swollen

11. Clypeus - punctation density: (0) dense, separated by 1-2 puncture diameters; (1) moderate, separated by 2-4 puncture diameters

12. Labrum - inflation: (0) swollen; (1) not swollen

13. Labrum - subapical setal row: (0) six to seven erect setae; (1) seven to eight erect setae; (2) ten to fourteen erect setae

14. Epipharynx - anterior setal row: (0) with six stout spiniform setae; (1) with eight or more stout spiniform setae

15. Epipharynx - anterolateral margins: (0) lacking setation; (1) with stout spinose setae; (2) with micro-setation

16. Epipharnyx - anterior spinule arrangement: (0) two semi uniform rows or irregular cluster; (1) two rows, each with two posterior papillae and one near the anterior margin

17. Tormae: (0) weakly asymmetric, more irregularly shaped and somewhat acute; (1) strongly asymmetric, broadly triangular and acute

18. Ligula - setae: (0) apex with fringe of 6-10 long setae medially with longitudinal row of short stout setae; (1) apex with median longitudinal row of microsetae dorsally two long subapical setae present ventrally; (2) apex densely microsetose two long subapical setae present ventrally; (3) apex lacking microsetae, two long subapical setae present ventrally, eight or more subapical setae present dorsally; (4) apex glabrous, four long subapical setae present two ventrally and two dorsally

19. Hypopharyngeal sclerome: (0) pentagonal, tricuspidate; (1) trapezoidal 
20. Gula: (0) trapezoidal, widest at base; (1) distinct, hexagonal to nearly rectangular, widest near middle

21. Gula - length: (0) equal to or less than maximum width; (1) greater than maximum width

22. Antennae: (0) three segmented, cylindrical, first segment shorter than second; (1) three segmented, cylindrical, first segment longer than second; (2) three segmented, cylindrical, first segment subequal to second

23. Prothoracic tergum - anterior transverse striated band: (0) present along anterior fourth, darker than tergal disc; (1) present along anterior fourth, lighter than tergal disc

24. Mesothoracic tergite - sclerotized transverse line: (0) absent; (1) present on anterior fifth, heavily sclerotized; (2) present on anterior fifth, faintly indicated

25. Metathoracic tergite - sclerotized transverse line: (0) absent; (1) present on anterior fifth, heavily sclerotized; (2) present on anterior fifth, faintly indicated

26. Thoracic tergites - setae: (0) eight evenly arranged setae present on dorsal surface of each thoracic tergite, lateral margins more densely setose; (1) more than eight dorsal setae present, pattern variable

27. Prothoracic tergum - shape: (0) subquadrate, $1.5 \times$ length of meso- or metaterga; (1) wider than long, $1.2 \times$ or more length of meso- or metaterga

28. Prothoracic tergum - lateral margins: (0) granulated band faint, concolourous with protergal disc; (1) granulated band distinct, darker than protergal disc; (2) granulated band absent

29. Meso- and metaterga - lateral margin: (0) pigmented bands present; (1) lacking pigmented bands

30. Prothoracic legs: (0) slightly longer and slightly thicker than meso- and metathoracic legs; (1) slightly longer and much thicker than meso- and metathoracic legs

31. Prothoracic legs - tarsungulus: (0) strongly sclerotized, attenuated and slightly hooked; (1) strongly sclerotized and sickle shaped

32. Prothoracic legs - tibia: (0) with ventro-medial row of three to four spines; (1) with ventro-medial row of five to six spines; (2) with ventro-medial row of eight to eleven spinose setae; (3) with eight or more spines ventro-medially not forming a regular row

33. Prothoracic legs - femur dorsal surface at rest: (0) with faintly indicated basal sclerotized band; (1) lacking basal sclerotized band

34. Abdominal sternites - color: (0) light tan; (1) dark tan; (2) ferruginous

35. Abdominal sternites I-VIII - transverse striated bands: (0) barely visible on posterior 5th of segments; (1) distinctly visible, forming near contiguous band with tergal band

36. Abdominal sternite I - setae: (0) sparsely clothed in long erect setae along anterior margin; (1) sparsely clothed in long erect setae from anterior margin to near midline; (2) moderately clothed in long erect setae to posterior pigmented band; (3) moderately clothed in long erect setae from anterior margin to near midline; (4) tomentose in anterior third, denser along near lateral margins 
37. Abdominal segments II-VIII - setae: (0) absent; (1) each segment with two sparse transverse bands of long erect setae; (2) each segment with two sparse transverse bands of long erect setae, posterior margin of segment 8 denser setal band; (3) otherwise

38. Abdominal tergites I-VIII - posterior margin color gradation: (0) dark along anterior edge, fading to segment color posteriorly; (1) unicolorous darker than rest of segment throughout

39. Abdominal tergite VIII - pigmentation: (0) more darkly pigmented than preceding segments; (1) same pigmentation as preceding segments

40. Abdominal tergite IX - pigmentation: (0) more darkly pigmented than preceding segments; (1) same pigmentation as preceding segments; (2) lighter than preceding segments

41. Abdominal laterotergites: (0) lateral margins distinctly pigmented; (1) concolorous with tergites, lacking distinct pigmented margins

42. Abdominal segment IX (pygidium) - shape: (0) triangular in dorsal view, gradually reflexed to apex, apex not forming a distinct tooth; (1) triangular in dorsal view, gradually reflexed to apex, apex attenuated and sclerotized forming a distinct tooth; (2) triangular in dorsal view, gradually reflexed to apex, apex attenuated and sclerotized rarely forming a small tooth in some specimens; (3) triangular in dorsal view, gradually reflexed to apex, apex with distinct urigomphi

43. Abdominal segment IX (pygidium) - setae: (0) few primary setae; (1) sparsely clothed in short and mid-length erect setae; (2) moderately clothed in short and mid-length erect setae

44. Abdominal segment IX (pygidium) - dorsal sculpturing: (0) dorsally more sclerotized in apical two thirds, with faint maculations; (1) sclerotization the same throughout, lacking maculations

45. Abdominal segment IX (pygidium) - marginal row of socketed spines: (0) four; (1) eight or more

46. Abdominal segment IX (pygidium) - marginal row of socketed spines 2: (0) four distinct regular spines; (1) forming a single row around posterior two thirds to one half of segment; (2) forming two or three irregular rows around posterior two thirds to one half of segment, narrowing to single row around apex

47. Abdominal segment $X$ - pygopods: (0) longer, tip inverted; (1) short, subconical

48. Abdominal segment $X$ - pygopod setation: (0) each 16 or less setae; (1) each with 17 or more setae 


\section{Appendix 4}

Cladistic Character Codings

\begin{tabular}{l|l}
\hline Eleodes_nigropilosus & 012001100111102002011202200101100011201100211110 \\
\hline Eleodes_tribulus & 002000001010002012011202200101100013211100211110 \\
\hline Eleodes_wheeleri & 013001101010102003010202201011110010111112111110 \\
\hline Eleodes_armatus & 003101101010102113010101101101120213111101111110 \\
\hline Eleodes_caudiferus & 112100011010212002010200010101110014311102211210 \\
\hline Eleodes_hispilabris & 103100000000211113010101101101121011211101111111 \\
\hline Eleodes_tenuipes & $00310000100021111301010120110112101111110121111 ?$ \\
\hline Eleodes_extricatus & 013001101000002002010101100101100011211100111110 \\
\hline Eleodes_anthracinus & 112011100111102014110111100011100101201110101110 \\
\hline Eleodes_carbonarius_knausi & 112011100111002004110111101011110101211210101110 \\
\hline Eleodes_goryi & 002011101010002012011201101101100013210000201110 \\
\hline Eleodes_subnitens & 002001101010102012011201201101110012211100211111 \\
\hline Eleodes_pilosus & $113110011010[01] 02012010102211101110012111100211111$ \\
\hline Tenebrio_molitor & 013001102000111011001001100100000010110003010000 \\
\hline Zophobas_morio & 000100000000000000000000000000031100000000000000 \\
\hline &
\end{tabular}

